Prepared for the U.S. Department of Energy under Contract DE-AC05-76RL01830

\title{
Extend EnergyPlus to Support Evaluation, Design, and Operation of Low Energy Buildings
}

$\mathrm{H}$ Cho

W Wang

A Makhmalbaf

K Yun

J Glazer

L Scheier

$\checkmark$ Srivastava

K Gowri

December 2011

\section{Pacific Northwest}

NATIONAL LABORATORY

Proudly Operated by Battelle Since 1965 


\title{
DISCLAIMER
}

This report was prepared as an account of work sponsored by an agency of the United States Government Neither the United States Government nor any agency thereof, nor Battelle Memorial Institute, nor any of their employees, makes any warranty, express or implied, or assumes any legal liability or responsibility for the accuracy, completeness, or usefulness of any information, apparatus, product, or process diselosed, or represents that its use would not infringe privately owned rights. Reference herein to any specific commercial product, process, or service by trade name, trademark, manufacturer, or otherwise does not necessarily constitute or imply its endorsement, recommendation, or favoring by the United States Government or any agency thereof, or Battelle Memorial Institute. The views and opinions of authors expressed herein do not necessarily state or reflect those of the United States Government or any agency thereof.

\author{
PACIFIC NORTHWEST NATIONAL LABORATORY \\ operated by \\ BATTELLE \\ for the \\ UNITED STATES DEPARTMENT OF ENERGY \\ under Contract DE-AC05-76RL01830 \\ Printed in the United States of America \\ Available to DOE and DOE contractors from the \\ Office of Scientific and Technical Information, \\ P.O. Box 62, Oak Ridge, TN 37831-0062; \\ ph: (865) 576-8401 \\ fax: (865) 576-5728 \\ email: reports@adonis.osti.gov
Available to the public from the National Technical Information Service,
ph: (800) 553-6847
fax: (703) 605-6900
email: orders $@$ ntis.fedworld.gov
online ordering: http://www.ntis.gov/ordering.htm \\ U.S. Department of Commerce, 5285 Port Royal Rd., Springfield, vA 2216
}

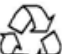

This document was printed on recycled paper.

(9/2003) 
PNNL-21021

\title{
Extend EnergyPlus to Support Evaluation, Design, and Operation of Low Energy Buildings
}

\author{
H Cho \\ W Wang \\ A Makhmalbaf \\ K Yun \\ J Glazer* \\ L Scheier** \\ V Srivastava \\ K Gowri
}

December 2011

\author{
Prepared for \\ U.S. Department of Energy \\ under Contract DE-AC05-76RL01830
}

Pacific Northwest National Laboratory

Richland, Washington 99352

* GARD Analytics

** SEl Associates 



\section{Executive Summary}

During FY10-11, Pacific Northwest National Laboratory in collaboration with the EnergyPlus development team implemented the following high priority enhancements to support the simulation of high performance buildings:

- Improve Autosizing of Heating, Ventilation, and Air Conditioning (HVAC) Components

- Life-Cycle Costing to Evaluate Energy Efficiency Upgrades

- Develop New Model to Capture Transformer Losses

- Enhance the Model for Electric Battery Storage

- Develop New Model for Chiller-Tower Optimization.

This report summarizes the technical background, new feature development and implementation details, and testing and validation process for these enhancements. The autosizing, life-cycle costing and transformer model enhancements/developments were included in EnergyPlus release Version 6.0, and the electric battery model development has been included in Version 7.0. The model development of chiller-tower optimization will be included in a future update of Version 7.0 . 


\section{Contents}

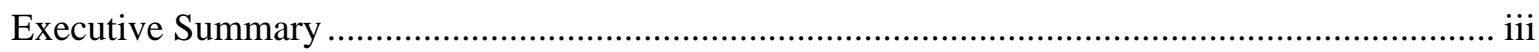

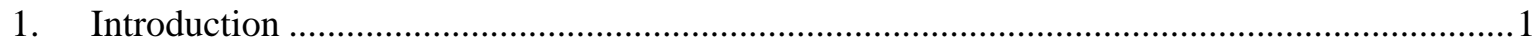

2. Improvement of Autosize Features for HVAC Components...................................................4

2.1 Variable Volume Fan Minimum Flow Rate................................................................. 4

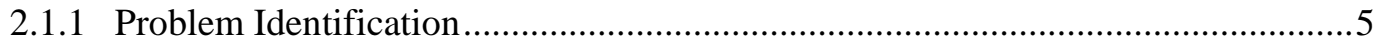

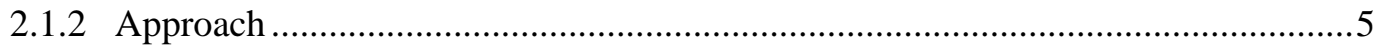

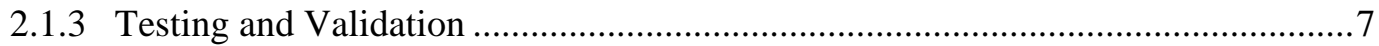

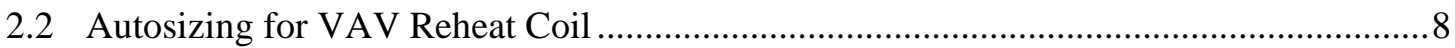

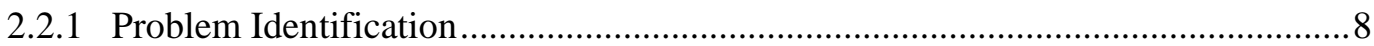

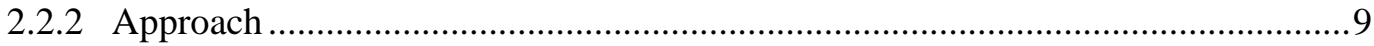

2.2.3 Testing and Validation .......................................................................................

2.3 Separate Sizing Factors for Air Volume Flow Rates, Heating Capacities, and Cooling

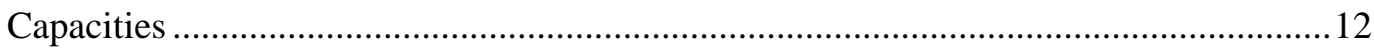

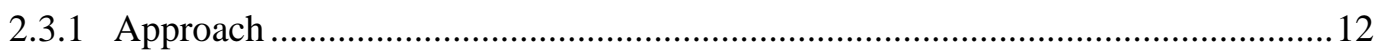

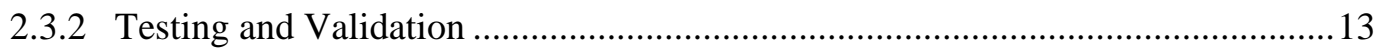

2.4 Autosizing for Zone Forced Air Units .......................................................................17

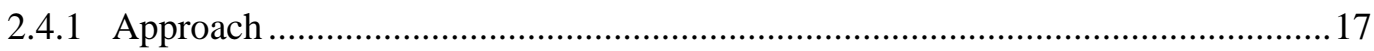

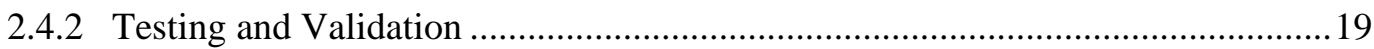

3. Development of an Electric Transformer Model ....................................................................2 23

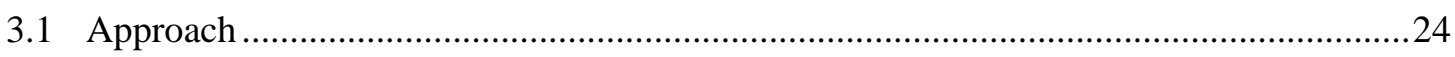

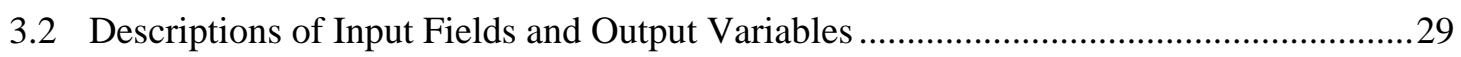

3.2.1 Input Fields for Transformer Model................................................................30

3.2.2 Output Variables for Transformer Model ........................................................33

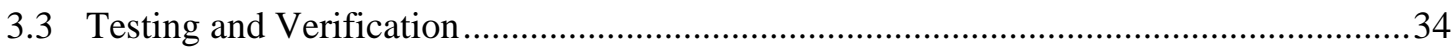

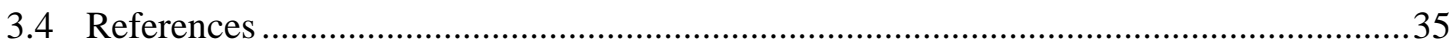

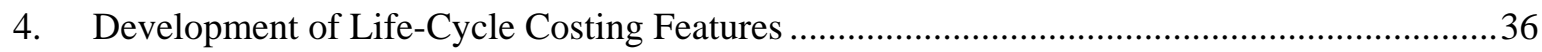

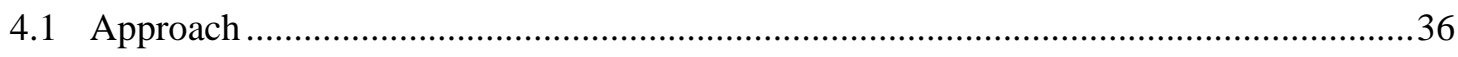

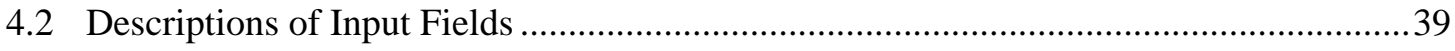

4.2.1 Input Fields for LifeCycleCost:Parameters ...........................................................39

4.2.2 Input Fields for LifeCycleCost:RecurringCosts ...................................................44

4.2.3 Input Fields for LifeCycleCost:NonrecurringCost ................................................46

4.2.4 Input Fields for LifeCycleCost:UsePriceEscalation...........................................47 
4.2.5 Input Fields for LifeCycleCost:UseAdjustment

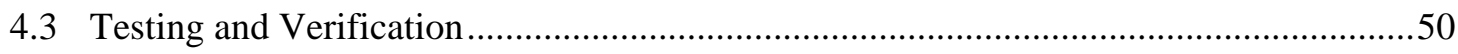

5. Development of an Electric Battery Model ….................................................................52

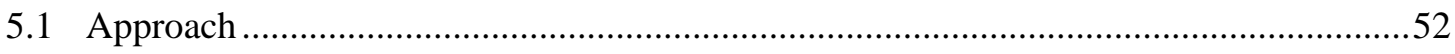

5.2 Descriptions of Input Fields and Output Variables .........................................................5

5.2.1 Input Fields for ElectricLoadCenter:Storage:Battery ...........................................57

5.2.2 Output Variables for ElectricLoadCenter:Storage:Battery ................................61

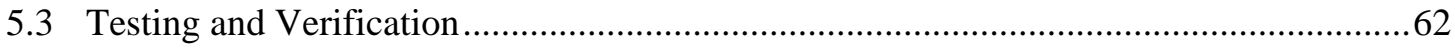

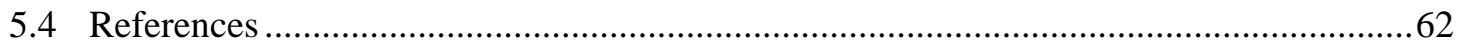

6. Development of a Chiller-Tower Optimization Model .........................................................64

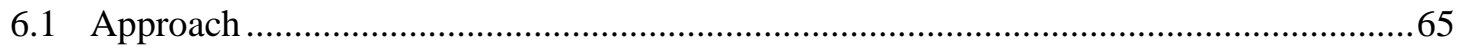

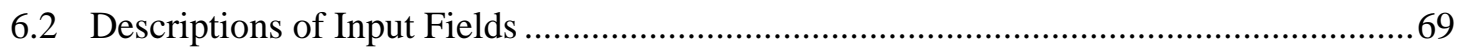

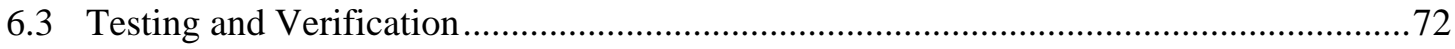

6.4 References ...................................................................... Error! Bookmark not defined.

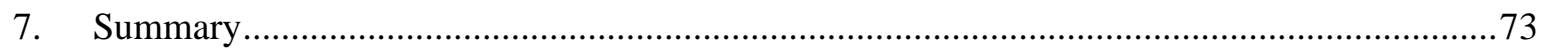




\section{Figures}

Figure 3-1. Flowchart for the implemented transformer model.................................................29

Figure 5-1: Electrical equivalent model for KiBaM ................................................................54

Figure 6-1: Total Energy Consumption vs. Condenser Water Temperature...................................64

Figure 6-2: Minimum tower design wet bulb temperature boundary condition ............................66

Figure 6-3: Minimum outdoor air wet bulb temperature boundary condition ...............................67

Figure 6-4: Optimized condenser entering water temperature as a function of weighted part load

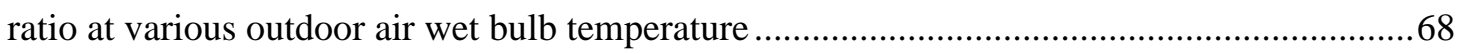




\section{Tables}

Table 2-1. Modified fields and values in each case …...................................................................5

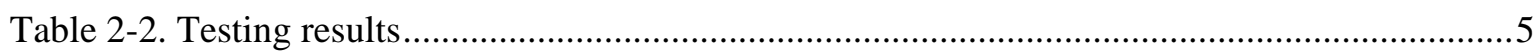

Table 2-3. Testing of ‘Fraction’ method...................................................................................

Table 2-4. Testing of 'FixedFlowRate' method........................................................................

Table 2-5. Zone heating sizing report with autosize feature in EnergyPlus V5.0...........................8

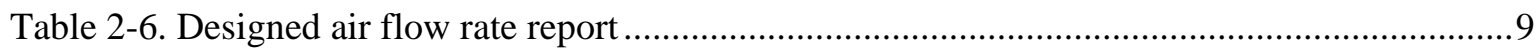

Table 2-7. Zone heating sizing results with manual maximum air flow rate inputs .........................9

Table 2-8. Zone heating sizing report with new autosize feature in EnergyPlus V6.0 ....................11

Table 2-9. Sizing factors entered in the testing example files .................................................... 13

Table 2-10. Zone design air flow rates and loads ................................................................... 16

Table 2-11. Zone cooling design load and air flow rate .........................................................19

Table 2-12. Zone heating design load and air flow rate............................................................ 19

Table 2-13. Zone cooling design air flow rate for EnergyPlus V5.0 ...........................................20

Table 2-14. Zone cooling design air flow rate for EnergyPlus V6.0 ...........................................20

Table 2-15. Mode changes of unit ventilators in the example file to test the new feature................20

Table 2-16. Zone cooling design load and air flow rate ..........................................................21

Table 2-17. Zone heating design load and air flow rate...........................................................21

Table 2-18. Zone supply air flow rate for EnergyPlus V5.0 …................................................21

Table 2-19. Zone supply air flow rate for EnergyPlus V6.0 …...................................................2

Table 2-20. Zone coil capacity for EnergyPlus V5.0 ….............................................................22

Table 2-21. Zone coil capacity for EnergyPlus V6.0 …............................................................22 


\section{Introduction}

The strategic goal of the U.S. Department of Energy’s (DOE’s) Building Technology Program (BTP) is to significantly increase the energy efficiency of new and existing buildings to reduce national energy demand and to develop marketable technologies and design approaches that address energy consumption in existing and new buildings. To achieve this goal, significant efforts are needed to develop analysis tools that can help designers in the evaluation and selection of advanced energy efficiency technologies. EnergyPlus is the premiere simulation tool currently available to address this need. Although the core capabilities of EnergyPlus are adequate to model high performance buildings, several additional capabilities are needed for evaluating low- and zero-energy buildings.

Pacific Northwest National Laboratory (PNNL), in collaboration with the Energy Plus development team, contributes to model development activities to meet DOE's goals for analysis tools. In FY10, PNNL identified three high priority features critical for extending the capabilities of EnergyPlus for supporting the design and evaluation of net-zero energy buildings, and the features were developed and integrated into Version 6.0 of EnergyPlus. These features are briefly described below.

\section{Improve Autosizing of Heating, Ventilation, and Air Conditioning (HVAC) Components}

Autosizing of HVAC components is a vital feature in EnergyPlus because it provides users great flexibility to model and evaluate various type of HVAC systems for buildings. It is critical to have proper mechanisms to size the HVAC components. When the HVAC equipment is not properly sized, it would result in under- or over-estimation of energy savings. Several deficiencies in EnergyPlus. Version 5.0, were identified and reported by the EnergyPlus development team. The following autosizing features were improved in FY10 and implemented in EnergyPlus version 6.0:

- Variable Volume Fan Minimum Flow Rate (discussed in Section 2.1)

- Autosizing for Variable Air Volume (VAV) Reheat Coil (discussed in Section 2.2)

- Separate Sizing Factors for Air Volume Flow Rates, Heating Capacities, and Cooling Capacities (discussed in Section 2.3)

- $\quad$ Autosizing for Zone Forced Air Units (discussed in Section 2.4).

A detailed analysis of the above improvements is presented in Section 2. 


\section{Life-Cycle Costing to Evaluate Energy Efficiency Upgrades}

Building energy simulation is often coupled with life-cycle costing to justify energy efficiency upgrades. Although EnergyPlus currently supports economic analysis of first cost and utility costs, it lacks the capability to perform life-cycle cost analysis. The Building Life Cycle Costing software BLCC5, developed by National Institute of Standards and Technology (NIST), is widely used and adapted by the Federal Energy Management Program for evaluating energy efficiency upgrades. PNNL reviewed the BLCC5 analysis methods and data requirements and integrated this analysis into EnergyPlus. PNNL developed a life-cycle cost computation module for the EnergyPlus simulation engine based on the method described in the NIST Handbook $135^{1}$. The scope of life-cycle cost calculation methods and input options was limited to evaluation of materials, equipment and system objects supported by EnergyPlus, Version 5.0. More detailed information of this feature is described in Section 3.

\section{Develop New Model to Capture Transformer Losses}

Transformers are an essential component to connect the distributed power generation systems in buildings with the electric grid. A transformer steps up the voltage when exporting excess on-site power and steps down voltage when importing power from the electric grid for on-site use. The power losses in voltage transformers need to be considered when modeling on-site power generation systems in buildings. Transformer losses can be significant, especially when approaching zero-energy building levels and modeling on-site power generation. PNNL developed a simple model for transformers capturing the power losses at both full load and part load conditions. An analysis of transformer development is provided in Section 4.

In FY11, PNNL proposed to extend the capabilities of EnergyPlus to address two high priority features identified in the EnergyPlus Enhancements list. These two feature development tasks are described below:

\section{Enhance the Model for Electric Battery Storage}

Distributed on-site power generation in buildings is one potential technological solution to achieve the net-zero energy building design goal. Representative technologies include micro-

${ }^{1}$ Fuller, SK and SR Petersen, 1995, Life-Cycle Costing Manual for the Federal Energy Management Program, NIST, Washington, DC. Available at: http://www.fire.nist.gov/bfrlpubs/build96/art121.html 
cogeneration and building-integrated photovoltaics (PVs) and wind turbines. Because to the inherent temporal mismatch between electrical production and consumption at the building level, electrical storage is an important component in distributed power systems. However, EnergyPlus currently has a very simple electrical storage model named "ElectricLoadCenter:Storage:Simple.” This is a simple

"bucket" model for electrical storage because it involves basic accounting of the energy flows and losses to determine the state of charge (SOC) over time. The current simple model does not represent any of the characteristics of a real secondary battery, such as the voltage-current relationship and the change of usable capacity with SOC. All these limitations make it necessary to develop more accurate battery models in EnergyPlus. In FY11, PNNL enhanced the battery storage model in EnergyPlus based on battery models implemented in other building simulation programs such as TRNSYS and ESP-r. This feature was added to Version 7.0 of EnergyPlus. This feature enhancement is summarized in Section 5.

\section{Develop New Model for Chiller-Tower Optimization}

Cooling tower models are normally used as components assigned to condenser loops to maintain the temperature of the water exiting the cooling tower at (or below) a set point. In EnergyPlus, Version 6.0, this set point is defined by the minimum condenser water temperature. To fully optimize a cooling plant, it is important to optimize cooling tower controls. The goal of cooling tower optimization is to find the optimal cooling tower water set point temperature that will result in minimum net energy consumption for the chiller and cooling tower plant. Therefore, EnergyPlus should add cooling tower optimization to give users the capability to have a better understanding of net energy consumption of the system and how to reach an optimized chiller/tower operation. This feature will be added to the future version of EnergyPlus. More detailed information of this feature development is described in Section 6. 


\section{Improvement of Autosize Features for HVAC Components}

Autosizing of HVAC components is a vital feature in EnergyPlus because it provides users great flexibility and resolution in modeling and evaluation of various types of HVAC systems for buildings without the time-consuming manual sizing process. When the "autosize" feature is used, it is critical to have proper mechanisms to size the HVAC components. When the HVAC equipment is not properly sized, it would result in under- or over-estimation of energy savings.

The EnergyPlus development team identified several enhancements to the equipment and system sizing features based on user requests and limitations in modeling new technologies. The following deficiencies were addressed as high priority during FY10, and the improved features were implemented in Version 6.0 of EnergyPlus:

a. VAV systems that can operate at low flow often have mismatching fan minimum flow specified or autosized. This can result in air loop solution non-convergence.

b. Some system configurations, such as VAV with a central heating coil can result in oversized plant equipment.

c. Reheat coils are sized to provide the specified supply air temperature at minimum flow or full flow (depending on the terminal unit type and damper heating action) regardless of how this compares with the zone peak heating requirement. This can result in undersized or oversized reheat coils, which can impact boiler sizing as well.

d. Different sizing factors need to be supported for cooling and heating equipment as required by ASHRAE Standard 90.1 and/or other codes.

e. Autosizing algorithms for zone forced air units appear to use the strategies for autosizing central air systems, which results in oversizing the equipment when the zone unit is only providing either heating or cooling but not both.

To address the deficiencies listed above, several new feature enhancement tasks were performed in FY10. A description of each task is summarized in the following subsections.

\subsection{Variable Volume Fan Minimum Flow Rate}

In Version 5.0 of EnergyPlus, the variable volume fan object exists and is used to vary the air volume supply to the zones through the ducts. In the object, users can specify a minimum air volumetric flow rate $\left(\mathrm{m}^{3} / \mathrm{sec}\right)$ for the fan at standard temperature and pressure. This user input is entered in the 
minimum flow rate field. This field can be autosized when users desire (i.e., when users specify it as “autosize”). This input field is confusing for users because it is only used for fan energy calculation and does not have any connection to the actual system minimum air flow in the simulation. This can cause unexpected results for users because the actual minimum air flow rate in the fan does not match with the minimum value used in the fan energy calculation. Because of this setting, it is possible that in some cases there would be very small or no fan energy reduction when the actual minimum flow goes far below the specified or autosized minimum flow rate in fan object. The feature to set the fan minimum power level can be further improved by the proposed method described below.

\subsubsection{Problem Identification}

An existing example idf file, 5ZoneAutoDXVAV.idf, was tested to demonstrate the deficiency discussed above. The modifications made in the testing idf files are described in Table 2-1. The testing results for each case are shown in Table 2-2.

Table 2-1. Modified fields and values in each case

\begin{tabular}{|c|c|c|c|}
\hline Field/Object & Original (Baseline) & Case1 & Case2 \\
\hline Min. Flow Rate/ Variable Volume Fan & Autosize $\left(0.35 \mathrm{~m}^{3} / \mathrm{sec}\right)$ & $1.5 \mathrm{~m}^{3} / \mathrm{sec}$ & $1.5 \mathrm{~m}^{3} / \mathrm{sec}$ \\
\hline Min. Flow Fraction/ VAV Reheat Terminal Unit & 0.1 & 0.1 & 0.4 \\
\hline
\end{tabular}

Table 2-2. Testing results

\begin{tabular}{|c|c|c|c|}
\hline & Original (Baseline) & Case1 & Case2 \\
\hline Total Site Energy & $7.85 \mathrm{GJ}$ & $7.86 \mathrm{GJ}$ & $7.94 \mathrm{GJ}$ \\
\hline Fan Energy & $0.88 \mathrm{GJ}$ & $0.90 \mathrm{GJ}$ & $0.90 \mathrm{GJ}$ \\
\hline Actual System Min. Flow & $0.300 \mathrm{~m}^{3} / \mathrm{sec}$ & $0.301 \mathrm{~m}^{3} / \mathrm{sec}$ & $0.924 \mathrm{~m}^{3} / \mathrm{sec}$ \\
\hline Actual System Max. Flow & $2.310 \mathrm{~m}^{3} / \mathrm{sec}$ & $2.310 \mathrm{~m}^{3} / \mathrm{sec}$ & $2.310 \mathrm{~m}^{3} / \mathrm{sec}$ \\
\hline
\end{tabular}

The results show that there are no connections between fan minimum flow rate specified or autosized in fan object and the actual terminal unit flow rate (i.e., no fan energy changes between Cases 1 and 2). The results also show that the fan energy did not decrease even if the actual minimum flow rate got decreased from Case 2 to Case 1. The total site energy results confirm that other energy, excluding fan energy, got decreased when the flow rates were allowed to decrease from $0.924 \mathrm{~m}^{3} / \mathrm{sec}$ to $0.301 \mathrm{~m}^{3} / \mathrm{sec}$.

\subsubsection{Approach}

The minimum flow rate field in the variable volume fan object is used to calculate fan power. This field exists because in reality variable speed fans have a minimum power level. To avoid the problem 
described above and to increase usability, it is recommended to remove the autosize feature in the minimum flow rate field and expand this field to include the following fields:

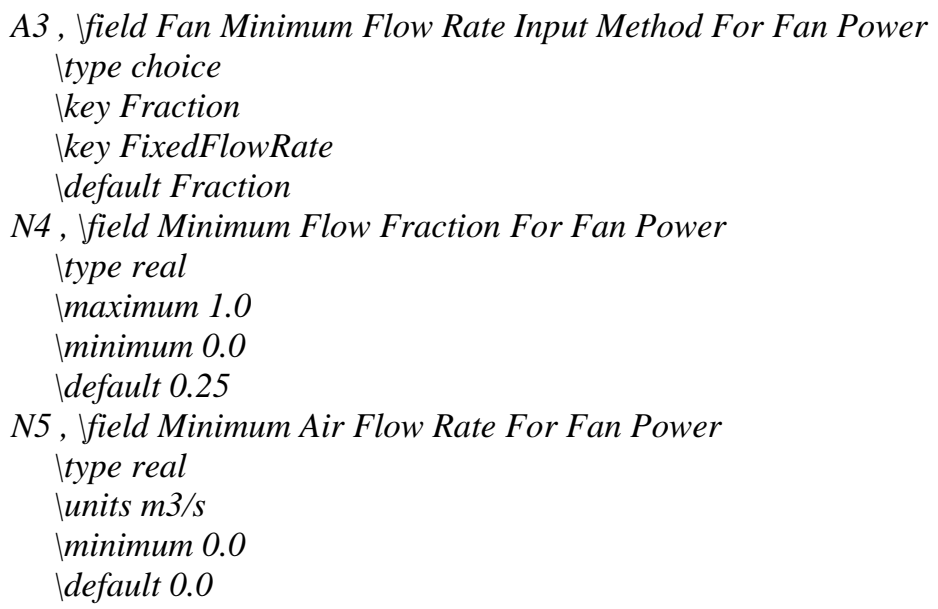

Each proposed field is explained in detail as follows:

\section{Field: Fan Minimum Flow Rate Input Method For Fan Power}

This field is used to select how the program will determine the fan minimum flow rate in the fan power calculation. There are two choices for selecting how the minimum flow rate is specified: Fraction and Flow Rate. If Fraction is entered, then the program will use the value for the minimum air flow fraction entered in the following field. If Flow Rate is entered, then the program will use the value entered in the field below called Minimum Air Flow Rate.

\section{Field: Minimum Flow Fraction For Fan Power}

The minimum air volumetric flow rate for fan power, specified as a fraction of maximum system air flow rate. Must be between 0 and 1. Note that this field is only used to calculate the fan power. This field does not enforce the system air flow rate during simulation.

\section{Field: Minimum Air Flow Rate For Fan Power}

The minimum air volumetric flow rate for fan power, specified as a constant minimum air flow rate $\left(\mathrm{m}^{3} / \mathrm{sec}\right)$. Note that this field is only used to calculate the fan power. This field does not enforce the system air flow rate during simulation.

The autosize feature was removed because it does not add much value to this feature. The term "for fan power" is recommended to be added to each field name to clarify the purpose. The minimum flow fraction will be used as the default method and the fraction value of 0.2 will be used as the default value. In addition, a note is added in Input and Output Reference to clarify the purpose of this field. 


\subsubsection{Testing and Validation}

After implementation of the new feature described in the previous section, the new feature was tested using the example file, 5ZoneAutoDXVAV.idf. Energy+.idd was also modified because the new input fields in Fan:VariableVolume object were added. First, the fan minimum flow input method of 'Fraction' was tested. The default value of 0.25 was used in the testing. No change in the results occurred. The fraction value was increased to 0.9 in the testing. The results showed that the fan energy use increased from $0.88 \mathrm{GJ}$ to $1.03 \mathrm{GJ}$. This increase was expected because the fan minimum flow is used to limit flow fraction to an allowed range and is ultimately used to calculate the fan power. Then the fan minimum flow input method of 'FixedFlowRate' was tested. A value of $0.578 \mathrm{~m} / \mathrm{s}$, which corresponds to the default fraction value of 0.25 , was initially used in the testing. No change in the results was found. Then the fixed flow rate was increased to $2.0 \mathrm{~m}^{3} / \mathrm{s}$. The results showed that the fan energy use increased from 0.88 GJ to 0.99 GJ. This result was also expected. The results before and after changes for each method are shown in Tables 2-3 and 2-4.

Table 2-3. Testing of ‘Fraction’ method

\begin{tabular}{|c||c|c||c|c|}
\hline & Original (Version 5) & $\begin{array}{c}\text { New Feature - } \\
\text { Fraction Method }\end{array}$ & Original (Version 5) & $\begin{array}{c}\text { New Feature - } \\
\text { Fraction Method }\end{array}$ \\
\hline Min. Flow Rate & $0.578 \mathrm{~m}^{3} / \mathrm{sec}$ & & $2.079 \mathrm{~m}^{3} / \mathrm{sec}$ & \\
\hline Min. Fraction & & $\begin{array}{c}0.25 \\
\left(=0.578 \mathrm{~m}^{3} / \mathrm{sec}\right)\end{array}$ & $\begin{array}{c}0.9 \\
\left(=2.079 \mathrm{~m}^{3} / \mathrm{sec}\right)\end{array}$ \\
\hline Fan Energy & $0.88 \mathrm{GJ}$ & $0.88 \mathrm{GJ}$ & $1.03 \mathrm{GJ}$ & $1.03 \mathrm{GJ}$ \\
\hline
\end{tabular}

Table 2-4. Testing of 'FixedFlowRate' method

\begin{tabular}{|c||c|c||c|c|}
\hline & Original (Version 5) & $\begin{array}{c}\text { New Feature - } \\
\text { FixedFlowRate } \\
\text { Method }\end{array}$ & Original (Version 5) & $\begin{array}{c}\text { New Feature - } \\
\text { FixedFlowRate } \\
\text { Method }\end{array}$ \\
\hline Min. Flow Rate & $0.578 \mathrm{~m}^{3} / \mathrm{sec}$ & $0.578 \mathrm{~m}^{3} / \mathrm{sec}$ & $2.0 \mathrm{~m}^{3} / \mathrm{sec}$ & $2.0 \mathrm{~m}^{3} / \mathrm{sec}$ \\
\hline Fan Energy & $0.88 \mathrm{GJ}$ & $0.88 \mathrm{GJ}$ & $0.99 \mathrm{GJ}$ & $0.99 \mathrm{GJ}$ \\
\hline
\end{tabular}

When the wrong name was used in the fan minimum flow input method field, the following error message was provided:

\footnotetext{
** Severe ** Fan Minimum Flow Rate Input Method For Fan Power should be either Fraction or FixedFlowRate.

** ** Occurs in SUPPLY FAN 1 object.

** Fatal ** GetFanInput: Errors found in input. Program terminates.
} 


\subsection{Autosizing for VAV Reheat Coil}

The following deficiencies in Version 5.0 of EnergyPlus were identified and reported:

Reheat coils in variable air volume (VAV) boxes are sized to provide the specified supply air temperature at min flow or full flow (depending on the terminal unit type and damper heating action) regardless of how this compares with the zone peak heating requirement. This can result in undersized or oversized reheat coils, which can impact boiler sizing as well.

Some system configurations, such as VAV with central heating coil can result in oversized plant equipment. VAV system sizing minimum flow rate fixed at 0.3 can cause heating or preheat undersizing. The user has no direct control of this input, and if the system flow rates are autosized, there is no way that HVAC Template could compute a reasonable value. Appropriate autosizing results are critical. With the many assumptions defaulted behind the scenes by HVAC Template, it is important that these be appropriate.

Several testing simulations were performed to confirm the deficiencies described above and the testing results are summarized in Section 2.2.1. To enhance the above deficiencies, a single solution is proposed in Section 2.2.2, and the results from the proposed solution are tested and validated in Section 2.2.3.

\subsubsection{Problem Identification}

An existing example idf file, HVACTemplate-5ZoneVAVWaterCooled.idf, was tested to demonstrate the deficiency. The simulation results shown in Table 2-5 indicate that the reheat coils are oversized significantly.

Table 2-5. Zone heating sizing report with autosize feature in EnergyPlus V5.0

\begin{tabular}{|c|c|c|}
\hline & Design Zone Heating Load [W] & Design Reheat Coil Load [W] \\
\hline SPACE1-1 & 3692.57 & 13602.94 \\
\hline SPACE2-1 & 1612.51 & 10165.64 \\
\hline SPACE3-1 & 3650.44 & 12613.71 \\
\hline SPACE4-1 & 1607.61 & 12422.67 \\
\hline SPACE5-1 & 2737.09 & 15098.2 \\
\hline
\end{tabular}

The reason is that the reheat coils are sized based on the maximum of zone heating and cooling loads, as shown in Table 2-6, when the heating damper action is reversed. Note that in the input file, the maximum supply flowrate in the terminal VAV box is autosized, and damper action is reversed. 
Table 2-6. Designed air flow rate report

\begin{tabular}{|c|c|c|c|}
\hline & $\begin{array}{c}\text { User Heating Design Air } \\
\text { Flow }\left[\mathrm{m}^{3} / \mathrm{sec}\right]\end{array}$ & $\begin{array}{c}\text { User Cooling Design Air } \\
\text { Flow }\left[\mathrm{m}^{3} / \mathrm{sec}\right]\end{array}$ & $\begin{array}{c}\text { Reheat Coil Sizing Air } \\
\text { Volume Flow Rate }\left[\mathrm{m}^{3} / \mathrm{sec}\right]\end{array}$ \\
\hline SPACE1-1 & 0.114 & 0.284 & 0.283616 \\
\hline SPACE2-1 & 0.050 & 0.212 & 0.21195 \\
\hline SPACE3-1 & 0.113 & 0.263 & 0.262991 \\
\hline SPACE4-1 & 0.050 & 0.259 & 0.259008 \\
\hline SPACE5-1 & 0.189 & 0.315 & 0.314792 \\
\hline
\end{tabular}

Another simulation was performed to confirm that the autosizing of maximum flowrate is the source of the problem. In the simulation, the maximum air flow rates for each VAV box are manually entered using the zone heating design air flow. The simulation results in Table 2-7 show that the reheat coils sized properly comparing the results in Tables 2-5 and 2-6. This confirms that the autosizing of maximum flow rate is the source of the problem.

Table 2-7. Zone heating sizing results with manual maximum air flow rate inputs

\begin{tabular}{|c|c|c|}
\hline & Design Zone Heating Load [W] & $\begin{array}{c}\text { Reheat Coil Sizing Air Volume } \\
\text { Flow Rate [m } / \mathrm{sec}]\end{array}$ \\
\hline SPACE1-1 & 4556.44 & 0.095 \\
\hline SPACE2-1 & 2014.43 & 0.042 \\
\hline SPACE3-1 & 4508.48 & 0.094 \\
\hline SPACE4-1 & 1966.46 & 0.041 \\
\hline SPACE5-1 & 3357.38 & 0.07 \\
\hline
\end{tabular}

\subsubsection{Approach}

From the several tests of HVACTemplate-5ZoneVAVWaterCooled.idf, it was revealed that the HVAC template itself does not have problems regarding reheat coil sizing issues. The problem occurs during the autosizing process for VAV reheat coil: see the testing results in Section 2.2.1. The problem is that the VAV maximum supply flow rate sizes off the maximum of heating and cooling flow rates when the damper action is reversed. It was confirmed that this is seen in the code, HVACSingleDuctSystem.f90. It is also seen in the code that the flow rate sizes off the minimum fraction of the maximum flow of heating and cooling flow rates if the minimum fraction flow rate is specified by users. The VAV sizing algorithm from HVACSingleDuctSystem.f90 is shown below: 


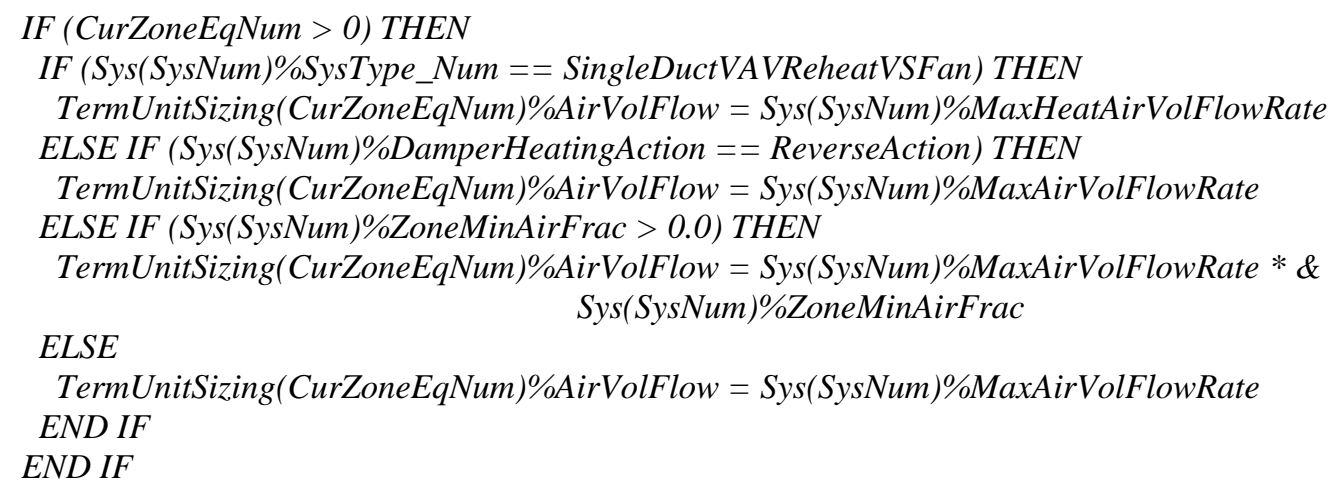

In the code, the maximum air volume flowrate (MaxAirFlowRate) is determined as follows if it is autosized:

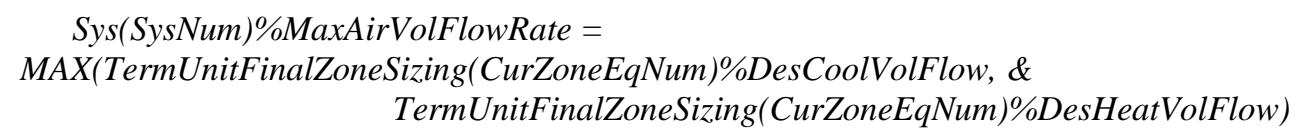

If cooling load is larger than heating load, the reheat coil would be oversized. Therefore, the reheat coil should be sized based on the zone peak heating load. As also confirmed with several HVAC engineers at PNNL, the reheat coil should size off the zone peak heating load. Then, this problem can be solved by sizing the reheat coils based on the design heating supply air flow rate (i.e., peak heating load) of the corresponding zone regardless of damper action and/or system type. When the heating load is too low for some zones, it is possible to undersize the reheat coil. Therefore, the minimum fraction flow rate is used to set the minimum level of terminal unit flow rate when the design heating flow rate is smaller than the minimum fraction flow rate. Then the following logic applies to the new feature enhancement.

If the terminal unit is VAV, the maximum air flow is determined as:

$$
V_{\text {air }, \text { max, terminal }}=\operatorname{Max}\left(\text { DesHeatVolFlowzone, FraCair }, \text { min }^{*} \text { DesVolFlowzone }\right)
$$

where, Fracair,min corresponds to the minimum flow fraction of the terminal unit. This value is provided as user input, typically as the field "Zone Minimum Air Flow Fraction.” For the VAV terminals that allow scheduling minimum flow fraction (e.g., AirTerminal:SingleDuct:VAV:Reheat), there are two ways that Fracair,min can be determined. If a value is entered in the input field Constant Minimum Air Flow Fraction, then it is always used for Fracair,min. If the minimum air flow fraction method is "Schedule" and the Constant Minimum Air Flow Fraction is left blank, then the program uses the average of the minimum and maximum values in the schedule for Fracair,min. 
Then the code can be modified as follows:

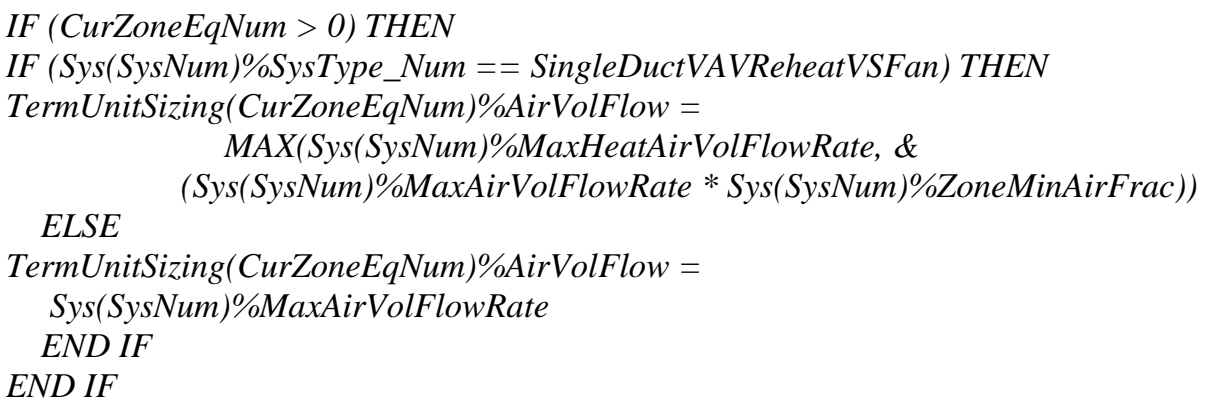

\subsubsection{Testing and Validation}

After implementation of new feature described in the previous section, the new feature was tested using the example file, HVACTemplate-5ZoneVAVWaterCooled.idf. The results in Table 2-8 illustrate that the coils are reasonably sized compared to the results in Table 2-7.

Table 2-8. Zone heating sizing report with new autosize feature in EnergyPlus Version 6.0

\begin{tabular}{|c|c|c|}
\hline & Design Zone Heating Load [W] & $\begin{array}{c}\text { Reheat Coil Sizing Air Volume } \\
\text { Flow Rate [m } / \mathrm{sec}]\end{array}$ \\
\hline SPACE1-1 & 5470.17 & 0.114051 \\
\hline SPACE2-1 & 3049.69 & 0.063585 \\
\hline SPACE3-1 & 5407.75 & 0.112750 \\
\hline SPACE4-1 & 3726.80 & 0.077702 \\
\hline SPACE5-1 & 9055.33 & 0.188800 \\
\hline
\end{tabular}

The hourly simulation results were also verified that adequate heating and cooling can be provided using the reduced design coil sizes. A very small difference in the end energy use was examined. It occurred because the coils and boiler capacities got smaller. As the capacities of coils and boiler changes, the performance of coils and boiler also got changed. This eventually caused a slight difference in end energy use. 


\subsection{Separate Sizing Factors for Air Volume Flow Rates, Heating Capacities, and Cooling Capacities}

In Version 5.0 of EnergyPlus, a single sizing factor was used to modify both heating and cooling equipment capacities based on the zone sizing calculation results. This limits users to comply with building energy code requirements in their simulations and also confines flexibility for users. For example, Appendix G in ASHRAE 90.1 Standard 2010 requires two separate quantities to specify sizing factors for the heating and cooling equipment capacities:

G3.1.2.2 Equipment Capacities. The equipment capacities (i.e., system coil capacities) for the baseline building design shall be based on sizing runs for each orientation (per Table G3.1, No. 5a) and shall be oversized by 15\% for cooling and 25\% for heating, i.e., the ratio between the capacities used in the annual simulations and the capacities determined by the sizing runs shall be 1.15 for cooling and 1.25 for heating.

With this version of EnergyPlus, such codes cannot be tested in their simulations. Therefore, separate sizing factor inputs for heating and cooling capacities are a necessary feature in EnergyPlus.

\subsubsection{Approach}

In EnergyPlus, there are two objects in which users can enter the sizing factors: Sizing Parameters (object: Sizing:Parameters) and Zone Sizing (object: Sizing:Zone). If entered in the Sizing Parameters statement, the sizing factor is applied to all systems. If entered in the Zone Sizing statement, the sizing factor is applied to a specific zonal system. Then using the sizing factor, new zone heating and cooling loads and air flow rates are determined and used to calculate the system level flow rates and capacities. These values are also used in all component sizing calculations.

The deficiency described above can be simply solved by separating a single sizing factor variable to two variables, i.e., heating and cooling sizing factors, in Sizing Parameters and in Zone Sizing objects. In Sizing Parameters object, the following fields can be used to replace the single sizing factor:

\section{Field: Heating Sizing Factor}

The global heating sizing ratio applied to all of the zone design heating loads and air flow rates.

\section{Field: Cooling Sizing Factor}

The global cooling sizing ratio applied to all of the zone design cooling loads and air flow rates. 
In Zone Sizing object, the following fields can be used to replace the single sizing factor:

\section{Field: Zone Heating Sizing Factor}

This input is a zone level heating sizing ratio. The zone design heating air flow rates and loads will be multiplied by the number input in this field. This input overrides the building level heating sizing factor input in the Sizing:Parameters object.

\section{Field: Zone Cooling Sizing Factor}

This input is a zone level cooling sizing ratio. The zone design cooling air flow rates and loads will be multiplied by the number input in this field. This input overrides the building level cooling sizing factor input in the Sizing:Parameters object.

\subsubsection{Testing and Validation}

After implementation of the new feature described in the previous section, the new feature was tested using an existing example file, DDAutoSize.idf. A single sizing factor of 1.0 in the Sizing Parameter object is used in the original example file. With the new feature, this was modified to two sizing factors in the Sizing Parameter object: a heating sizing factor of 1.0 and a cooling sizing factor of 1.0. The simulation results with the new feature show no changes in the end energy use results and the sizing of components compared to the results with the EnergyPlus V5.0.

The example file was further modified to test that two separate sizing factors works as expected. In the example input file, the heating sizing factor was changed from 1.0 to 1.5, and the cooling sizing factor was changed from 1.0 to 1.2, as shown in Table 2-9.

Table 2-9. Sizing factors entered in the testing example files

\begin{tabular}{|c|c|c|}
\hline & Case 1 (Original) & Case 2 (Modified) \\
\hline Heating Sizing Factor & 1.0 & 1.5 \\
\hline Cooling Sizing Factor & 1.0 & 1.2 \\
\hline
\end{tabular}

The results presented in 
Table 2-10 show that the sizing factors are properly applied to determine the zone design air flow rates and loads. The ratios of cases 1 and 2 are calculated and provided in 
Table 2-10. 
Table 2-10. Zone design air flow rates and loads

\begin{tabular}{|c|c|c|c|}
\hline & \multicolumn{2}{|c|}{ Heating User Design Air Flow $\left[\mathrm{m}^{3} / \mathrm{sec}\right]$} & \\
\hline & Case 1 & Case 2 & Ratio (Case 2 / Case 1) \\
\hline WEST ZONE & 0.105 & 0.158 & 1.5 \\
\hline EAST ZONE & 0.109 & 0.164 & 1.5 \\
\hline NORTH ZONE & 0.161 & 0.241 & 1.5 \\
\hline
\end{tabular}

\begin{tabular}{|c|c|c|c|}
\hline & \multicolumn{2}{|c|}{ Cooling User Design Air Flow $\left[\mathrm{m}^{3} / \mathrm{sec}\right]$} & \\
\hline & Case 1 & Case 2 & Ratio (Case 2 / Case 1) \\
\hline WEST ZONE & 0.488 & 0.586 & 1.2 \\
\hline EAST ZONE & 0.436 & 0.523 & 1.2 \\
\hline NORTH ZONE & 0.575 & 0.69 & 1.2 \\
\hline
\end{tabular}

\begin{tabular}{|c|c|c|c|}
\hline & \multicolumn{2}{|c|}{ Zone Heating Design Load [W] } & \\
\hline & Case 1 & Case 2 & Ratio (Case 2 / Case 1) \\
\hline WEST ZONE & 4685.58 & 7028.36 & 1.5 \\
\hline EAST ZONE & 4860.15 & 7290.23 & 1.5 \\
\hline NORTH ZONE & 7149.09 & 10723.64 & 1.5 \\
\hline
\end{tabular}

\begin{tabular}{|c|c|c|c|}
\hline & \multicolumn{2}{|c|}{ Zone Cooling Design Load [W] } & \\
\hline & Case 1 & Case 2 & Ratio (Case 2 / Case 1) \\
\hline WEST ZONE & 5866.86 & 7040.23 & 1.2 \\
\hline EAST ZONE & 5236.01 & 6283.22 & 1.2 \\
\hline NORTH ZONE & 6905.14 & 8286.17 & 1.2 \\
\hline
\end{tabular}




\subsection{Autosizing for Zone Forced Air Units}

In Version 5.0 of EnergyPlus, window air-conditioning (AC) and unit ventilator are not sized properly when they are autosized. The maximum flow rate gets sized to the larger of zone heating or cooling load. This can provide the users with wrong results. The following deficiencies in Version 5.0 of EnergyPlus were identified and reported:

Erroneous sizing of zone equipment will impact the energy use predictions by shifting operation to a different part of the part load ratio curve. Users may be relying on EnergyPlus to size equipment and not realize the zone equipment has been sized off of flow rates for the wrong type of load.

Autosizing algorithms for zone forced air units appear to mimic those of central air systems. This is deficient when the zone unit is only providing either heating or cooling but not both. Central air systems will nearly always be sized and used for both heating and cooling while zone equipment of different types may be combined to provide heating and cooling. For example, a Window AC unit's air flow rate will currently get sized to the larger of heating or cooling demands. If heating loads are much higher, the Window AC can be extremely oversized because of a heating flow rate that it will never provide. Autosizing of all types of zone unit equipment needs to be revised to include logic that sizes units off the specific type of load the particular equipment will actually meet. For example, a Window AC unit should size flow rate off the cooling load (and not the maximum of cooling and heating).

\subsubsection{Approach}

The zone forced air units in EnergyPlus are listed below:

- ZoneHVAC:IdealLoadsAirSystem

- ZoneHVAC:FourPipeFanCoil

- ZoneHVAC:WindowAirConditioner

- Unit Ventilator/Heater

- Air-to-Air Heat Pumps

- Unitary Systems (heat only and heat/cool)

- Furnaces (heat only and heat/cool)

- Energy Recovery Ventilator:Stand Alone

- AirLoopHVAC:UnitaryCoolOnly. 
Among these units, heat only or cool only units highlighted in red above were reviewed to check if the units currently size flow rate off the maximum of cooling and heating. It was identified that only the window air conditioner unit and unit ventilator size off the maximum of cooling and heating. Other units size off the proper zone load, e.g., heat only units size off heating load.

The sizing problem for the window air conditioner can simply be solved by fixing the source code (i.e., WindowAC.f90). In the source code of version 5.0, the following line can be found to determine maximum air volume flow rate:

\section{WindAC(WindACNum)\%MaxAirVolFlow = MAX(FinalZoneSizing(CurZoneEqNum)\%DesCoolVolFlow, \& FinalZoneSizing(CurZoneEqNum)\%DesHeatVolFlow)}

This can be replaced by the following line to correctly size flow rate:

WindAC(WindACNum)\%MaxAirVolFlow = FinalZoneSizing(CurZoneEqNum)\%DesCoolVolFlow

The sizing problem for the unit ventilator is more complicated. Unit ventilators are compound components: each unit contains an outdoor air mixer, a fan, a heating coil, and a cooling coil. The users can specify whether this unit can be no-heating/cooling, heating only, cooling only, or bothheating/cooling. The inputs that may need to be autosized are the maximum supply air flow rate and the maximum/minimum outside air flow rates. In the source code of Version 5.0, the maximum air flow rate sizes off the maximum of cooling and heating regardless of the heating/cooling mode. The following line can be found in the code:

\section{UnitVent(UnitVentNum)\%MaxAirVolFlow = MAX(FinalZoneSizing (CurZoneEqNum)\%DesCoolVolFlow, \& FinalZoneSizing(CurZoneEqNum)\%DesHeatVolFlow)}

This code can be corrected to properly size the flow rates as follows:

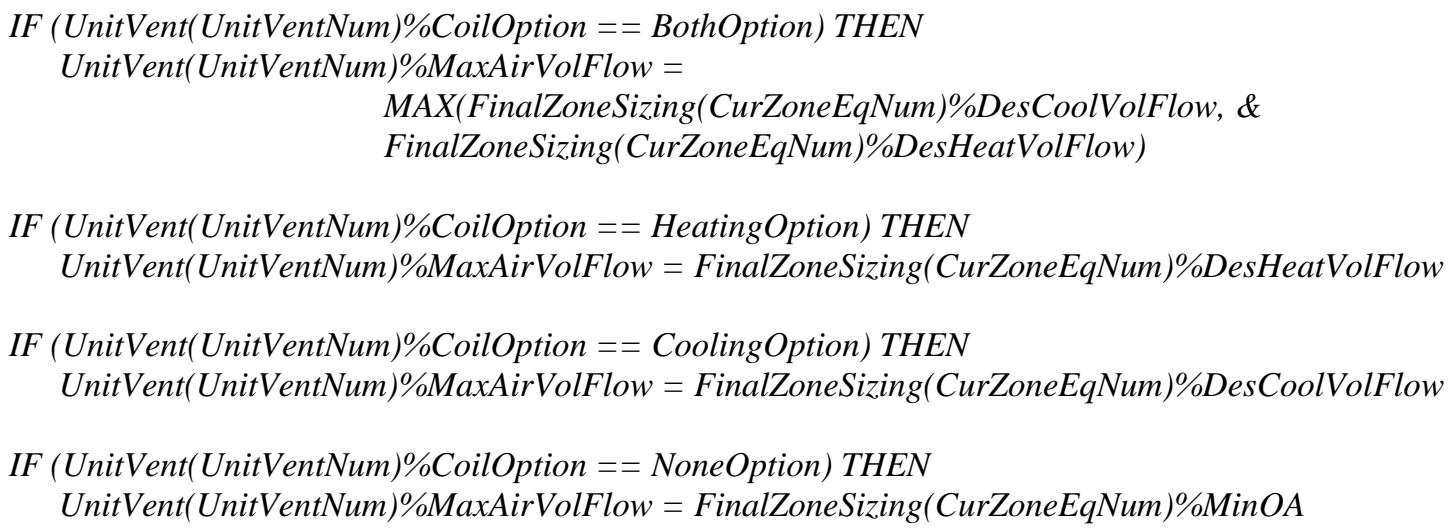




\subsubsection{Testing and Validation}

\section{Testing of New Feature - Window AC Object:}

After implementation of the new feature described in the previous section, the new feature was tested using an existing example file, WindACAuto.idf. No transitional change in the result was observed when the example file with the new feature was tested. The reason is that the design cooling maximum air volume flow rate for each zone was greater than the design heating maximum air volume flow rate for each zone.

To test the new code properly, the example file was further modified. The changes were made in zone cooling and heating design supply air temperature in the zone sizing objects for each zone. The aim for this modification was to decrease cooling maximum air volume flow rate and to increase heating maximum air volume flow rate, so that the design heating maximum air volume flow rate for each zone is greater than the design cooling maximum air volume flow rate for each zone. In the example idf file, the zone cooling design supply air temperature was changed from $12^{\circ} \mathrm{C}$ to $10^{\circ} \mathrm{C}$, while the zone heating design supply air temperature was reduced from $50^{\circ} \mathrm{C}$ to $45^{\circ} \mathrm{C}$. After the modification, the heating design air volume flow rates for east and north zones are shown to be greater than the cooling design air volume flow rate for those zones, as shown in Tables 2-11 and 2-12.

Table 2-11. Zone cooling design load and air flow rate

\begin{tabular}{|c|c|c|}
\hline & Design Load [W] & User Design Air Flow $\left[\mathrm{m}^{3} / \mathrm{sec}\right]$ \\
\hline WEST ZONE & 4365.09 & 0.260 \\
\hline EAST ZONE & 3293.65 & 0.196 \\
\hline NORTH ZONE & 4710.92 & 0.281 \\
\hline
\end{tabular}

Table 2-12. Zone heating design load and air flow rate

\begin{tabular}{|c|c|c|}
\hline & Design Load [W] & User Design Air Flow $\left[\mathrm{m}^{3} / \mathrm{sec}\right]$ \\
\hline WEST ZONE & 5834.02 & 0.195 \\
\hline EAST ZONE & 6783.11 & 0.226 \\
\hline NORTH ZONE & 10100.59 & 0.337 \\
\hline
\end{tabular}

The results in Tables 2-13 and 2-14 show that the new code is properly implemented and is working as expected. First, Version 5.0 code was tested. As described in previous section, the code "autosizes" the maximum supply air flow rate based on the maximum value between cooling and heating design air flow 
rate. Because the heating design flow rates in the east and north zones are greater than the cooling design flow rates in each zone respectively, the maximum supply air flow rates in the east and north zones size off the heating design flow rates for each zone, as shown in Table 2-13. As discussed in the previous section, the design flow of air conditioning units should not be sized based on the heating design flow rate.

Table 2-13. Zone cooling design air flow rate for EnergyPlus V5.0

\begin{tabular}{|l|c|c|}
\hline & Maximum Supply Air Flow Rate $\left[\mathrm{m}^{3} / \mathrm{sec}\right]$ & Maximum Outdoor Air Flow Rate $\left[\mathrm{m}^{3} / \mathrm{sec}\right]$ \\
\hline ZONE1WINDAC & 0.260076 & 0.028320 \\
\hline ZONE2WINDAC & 0.226282 & 0.028320 \\
\hline ZONE3WINDAC & 0.336951 & 0.037760 \\
\hline
\end{tabular}

Then the new code was tested. Table 2-14 shows that the maximum supply air flow rates for each zone are sized based on the design cooling flow rates for each zone when the new code is used.

Table 2-14. Zone cooling design air flow rate for EnergyPlus V6.0

\begin{tabular}{|l|c|c|}
\hline & Maximum Supply Air Flow Rate $\left[\mathrm{m}^{3} / \mathrm{sec}\right]$ & Maximum Outdoor Air Flow Rate $\left[\mathrm{m}^{3} / \mathrm{sec}\right]$ \\
\hline ZONE1WINDAC & 0.260076 & 0.028320 \\
\hline ZONE2WINDAC & 0.196240 & 0.028320 \\
\hline ZONE3WINDAC & 0.280679 & 0.037760 \\
\hline
\end{tabular}

\section{Testing of New Feature - Unit Ventilator Object:}

Version 5.0 code of UnitVentilator. 990 was modified based on the proposed method in the previous section. An existing example file, UnitVent5ZoneAuto.idf was used in the testing. To test all the modes described in the previous section, the example file was modified, as shown in Table 2-15.

Table 2-15. Mode changes of unit ventilators in the example file to test the new feature

\begin{tabular}{|c|c|c|}
\hline & Coil Option Before Changes & Coil Option After Changes \\
\hline Unit Ventilator 1 & HeatingAndCooling & HeatingAndCooling \\
\hline Unit Ventilator 2 & Heating & Heating \\
\hline Unit Ventilator 3 & Heating & Heating \\
\hline Unit Ventilator 4 & HeatingAndCooling & Cooling \\
\hline Unit Ventilator 5 & Heating & None \\
\hline
\end{tabular}


With the changes in the example file, Version 5.0 code was tested. Tables 2-16 and 2-17 show cooling and heating design load and air flow rate for each space.

Table 2-16. Zone cooling design load and air flow rate

\begin{tabular}{|c|c|c|}
\hline & Design Load [W] & User Design Air Flow $\left[\mathrm{m}^{3} / \mathrm{sec} \mathrm{s}\right]$ \\
\hline Zone 1 & 2898.75 & 0.241 \\
\hline Zone 2 & 2203.14 & 0.183 \\
\hline Zone 3 & 1599.96 & 0.133 \\
\hline Zone 4 & 2492.40 & 0.208 \\
\hline Zone 5 & 2992.93 & 0.249 \\
\hline
\end{tabular}

Table 2-17. Zone heating design load and air flow rate

\begin{tabular}{|c|c|c|}
\hline & Design Load [W] & User Design Air Flow $\left[\mathrm{m}^{3} / \mathrm{sec}\right]$ \\
\hline Zone 1 & 3795.96 & 0.104 \\
\hline Zone 2 & 1568.77 & 0.047 \\
\hline Zone 3 & 4206.42 & 0.115 \\
\hline Zone 4 & 1671.52 & 0.047 \\
\hline Zone 5 & 1198.85 & 0.189 \\
\hline
\end{tabular}

The results in Table 2-18 illustrate that the maximum supply flow rate in each zone sizes off the maximum of cooling and heating design values regardless of mode options. Table 2-19 demonstrates that the maximum supply flow rates are sized properly based on their mode options (e.g., in zones 2 and 3, the maximum supply flow rates are sized based on the heating design flow rate when "Heating” mode is selected and in zone 5, the maximum supply flow rates are sized based on the minimum outdoor air design flow rate when "None” mode is selected).

Table 2-18. Zone supply air flow rate for EnergyPlus V5.0

\begin{tabular}{|l|c|c|}
\hline & Maximum Supply Air Flow Rate [m3/s] & Maximum Outdoor Air Flow Rate [m3/s] \\
\hline ZONE1UNITVENT & 0.241409 & 0.241409 \\
\hline ZONE2UNITVENT & 0.183465 & 0.183465 \\
\hline ZONE3UNITVENT & 0.133215 & 0.133215 \\
\hline ZONE4UNITVENT & 0.207543 & 0.207543 \\
\hline ZONE5UNITVENT & 0.249271 & 0.249271 \\
\hline
\end{tabular}

Table 2-19. Zone supply air flow rate for EnergyPlus V6.0

\begin{tabular}{|l|c|c|}
\hline & Maximum Supply Air Flow Rate [m3/s] & Maximum Outdoor Air Flow Rate [m3/s] \\
\hline ZONE1UNITVENT & 0.241409 & 0.241409 \\
\hline ZONE2UNITVENT & 0.047200 & 0.047200 \\
\hline ZONE3UNITVENT & 0.114515 & 0.114515 \\
\hline ZONE4UNITVENT & 0.207543 & 0.207543 \\
\hline ZONE5UNITVENT & 0.188800 & 0.188800 \\
\hline
\end{tabular}


The results in Table 2-21 show that the new feature (i.e., EnergyPlus V6.0) fixes the coil oversizing problem compared to the results with Version 5.0 of EnergyPlus, as shown in Table 2-20.

Table 2-20. Zone coil capacity for EnergyPlus V5.0

\begin{tabular}{|c|c|c|}
\hline & Type & Nominal Total Capacity [W] \\
\hline ZONE1UNITVENTHEATINGCOIL & Coil:Heating:Water & 10921.70 \\
\hline ZONE2UNITVENTHEATINGCOIL & Coil:Heating:Water & 5690.63 \\
\hline ZONE3UNITVENTHEATINGCOIL & Coil:Heating:Water & 8015.63 \\
\hline ZONE4UNITVENTHEATINGCOIL & Coil:Heating:Electric & 3781.12 \\
\hline ZONE5UNITVENTHEATINGCOIL & Coil:Heating:Gas & 15124.49 \\
\hline
\end{tabular}

Table 2-21. Zone coil capacity for EnergyPlus V6.0

\begin{tabular}{|c|c|c|}
\hline & Type & Nominal Total Capacity [W] \\
\hline ZONE1UNITVENTHEATINGCOIL & Coil:Heating:Water & 10921.70 \\
\hline ZONE2UNITVENTHEATINGCOIL & Coil:Heating:Water & 3230.22 \\
\hline ZONE3UNITVENTHEATINGCOIL & Coil:Heating:Water & 7351.56 \\
\hline ZONE4UNITVENTHEATINGCOIL & NA & NA \\
\hline ZONE5UNITVENTHEATINGCOIL & NA & NA \\
\hline
\end{tabular}




\section{Development of an Electric Transformer Model}

Transformers are an integrated part of the electric distribution system. They have two broad applications closely related to building energy simulation. First, transformers are used to lower the voltage of electricity from utility primary circuits to customer secondary circuits. Second, transformers are used to output the surplus power from onsite generators to the electricity grid. Transformers experience energy losses when they are energized or change the electricity from one voltage to another for load requirement. In Version 5.0 of EnergyPlus, transformer losses cannot be modeled because of the lack of a transformer model. However, a user may want to investigate the impact of using high-efficiency distribution transformers on energy consumption. For example, Addendum O of ASHRAE Standard 90.12007 specifies the minimum efficiency requirement of distribution transformers. Without a transformer model, EnergyPlus cannot be conveniently used to estimate the energy saving potential with this addendum. The need to have a transformer model in building energy simulation is also observed through the discussions in simulation user groups.

Because modeling electric transformers is to be added as a brand new feature for EnergyPlus, a new object ElectricLoadCenter:Transformer is created. The transformer object is placed into the group of electric load center. This is mainly because a transformer is an electrical component, and electric load center is the only group used in EnergyPlus Version 5.0 to support power generation and power management. The new model is capable of modeling a transformer by capturing its energy losses and its interaction with the zone heat balance.

Energy losses in transformers consist of the no load (core) loss and the load (winding) loss. The no load loss is roughly constant and exists continuously in the core material as long as the transformer is energized. The load loss is proportional to the load squared with a small temperature correction. The new model can be used to estimate the energy losses for all types of distribution transformers (medium-voltage and low-voltage, dry type and liquid-immersed) used to transfer electricity from the grid to a building. The model can be also used for the transformers that transfer the surplus electricity from onsite generators to the grid.

For a distribution transformer, the load is derived from the readings of those electric meters wired to the transformer. For a transformer used to output electricity from onsite generators to the grid, the load is

the surplus power from each electric load center. Because different electric load centers may use different transformers, it is necessary to know which transformer is associated with each electric load center. 
Therefore, an optional field on transformer name is added to the object ElectricLoadCenter:Distribution, which already exists in EnergyPlus Version 5.0.

Given transformer load, energy losses depend on the transformer performance. The transformer object provides the user two alternative ways to indicate the transformer's performance. First, the user can provide the no-load loss and load loss at rated conditions. Second, the user can provide the nameplate efficiency and the corresponding reference conditions, based on which the model derives the rated load loss and rated no-load loss. Manufacturer datasheets were referred in the process of proposing the model input to make sure the inputs are readily available from the product catalog.

An approach used to model the transformer performance is presented in Section 3.1. Descriptions of input and output variables in the proposed transformer model are provided in Section 3.2. A verification of model performance is presented in Section 3.3.

\subsection{Approach}

Distribution transformers reduce the voltage on utility distribution lines (34.5 kV or less) to a lower secondary voltage (600 V or less) suitable for customer equipment. Distribution transformers are usually categorized according to the medium used for cooling and insulation (liquid or air), the voltage class that they serve (low or medium), and the number of phases (single phase or three phase).

Liquid-immersed transformers rely on oil or other fire resistant liquid around the coils for cooling. In contrast, dry type transformers rely only on the natural convection of air for insulation and cooling. Medium-voltage transformers step from utility line voltage down to a lower secondary voltage, depending on the application. The secondary voltage from a medium-voltage transformer is usually at $277 \mathrm{~V}$ for single phase and 480 for three phase. This secondary voltage can be directly used as $480 \mathrm{~V}$ three-phase power for large motors or as $277 \mathrm{~V}$ single-phase power for some fluorescent lighting. However, for most industrial and commercial facilities, low-voltage transformers are needed to reduce the above voltages further to 208/120 V. Common 120 V loads are wall plugs and incandescent lighting.

Most liquid-immersed transformers are owned by utilities, and they are of the medium-voltage type. Virtually all dry type transformers are owned by commercial and industrial customers (Barnes et al. 1996). Of the dry type transformers, those of the medium-voltage type are generally special-order items while those of the low-voltage type are commodity items. The efficiency requirement of distribution transformers is covered by the NEMA (National Electrical Manufacturers Association) Standard TP 1. 
ASHRAE 90.1-2010 will cite the NEMA Standard TP 1 to stipulate the efficiency requirement for the low-voltage dry type distribution transformers.

There are two main types of energy losses in transformers: no load loss and load loss. The no load loss comes primarily from the switching of the magnetic fields in the core material. Hence, it is also called the core loss. The no load (core) loss is roughly constant and exists continuously in the core material as long as the transformer is energized. The load loss comes from the electrical resistance in the windings when there is a load on the transformer. Hence, the load loss is also called the winding loss. The load (winding) loss is proportional to the load squared with a small temperature correction.

Given the no load loss (NL) and the load loss (LL) at rated load and conditions, the total energy losses in a transformer at time $\mathrm{t}$ is calculated as:

$T L(t)=N L+L L(t)=N L+L L * P(t)^{2} * f_{T}(t)$

where,

$T L(t) \quad$ Total energy loss at time $\mathrm{t}(\mathrm{W})$

$L L(t) \quad$ Load loss at time $\mathrm{t}(\mathrm{W})$

$P(t) \quad$ Per unit load at time $\mathrm{t}$

$f_{T}(t) \quad$ Temperature correction factor for the load loss at time t.

The per unit load at time $t$ is calculated as:

$P(t)=\frac{\operatorname{Load}(t)}{S_{B}}$

where,

$\operatorname{Load}(t) \quad$ Transformer load at time $\mathrm{t}(\mathrm{W})$

$S_{B} \quad$ Transformer nameplate rating (VA).

The temperature correction factor at time $t$ is calculated as (NEMA 2002):

$$
f_{T}(t)=L_{d c} * \frac{R(t)}{R_{r e f}}+L_{e d d y} * \frac{R_{r e f}}{R(t)}
$$


where,
$L_{d c} \quad$ Per unit load loss due to electrical resistance
$L_{\text {eddy }} \quad$ Per unit load loss due to eddy currents
$R(t) \quad$ Winding electrical resistance at time $\mathrm{t}$
$R_{\text {ref }} \quad$ Winding electrical resistance at the full load reference conditions.

The ratio of winding electrical resistance is calculated as:

$$
\frac{R(t)}{R_{\text {ref }}}=\frac{F+T_{\text {winding }}(t)+T_{\text {amb }}(t)}{F+T_{\text {winding,ref }}+T_{\text {amb,ref }}}
$$

where,

$$
\begin{aligned}
& F \quad \begin{array}{l}
\text { Thermal coefficient of resistance for the winding material }(=225 \text { for aluminum } \\
\text { and } 234.5 \text { for copper })
\end{array} \\
& T_{\text {winding,ref }} \quad \text { Winding temperature rise at the full load reference conditions }\left({ }^{\circ} \mathrm{C}\right) \\
& T_{\text {winding }}(t) \quad \text { Winding temperature rise at time } \mathrm{t}\left({ }^{\circ} \mathrm{C}\right) \\
& T_{\text {amb,ref }} \quad \text { Ambient temperature at the reference condition }\left(=20^{\circ} \mathrm{C}\right) \\
& T_{\text {amb }}(t) \quad \text { Ambient temperature at time } \mathrm{t}\left({ }^{\circ} \mathrm{C}\right) .
\end{aligned}
$$

The ambient temperature $T_{\text {amb }}(t)$ is equal to the zone temperature if a thermal zone is specified in the input; otherwise, it is assumed equal to $20^{\circ} \mathrm{C}$. The winding temperature rise at time $\mathrm{t}$ is calculated as (Barnes et al. 1997):

$$
\mathrm{T}_{\text {winding }}(\mathrm{t})=\mathrm{P}(\mathrm{t})^{1.6} * \mathrm{~T}_{\text {winding.ref }}
$$

Based on the derived total energy losses in a transformer, the transformer efficiency at time $t$ can be calculated according to the following equation:

$$
\eta(t)=\frac{\operatorname{Load}(t)}{\operatorname{Load}(t)+N L+L L(t)}
$$

The above procedure describes how to calculate the total transformer energy losses based on the no load loss and load loss at rated conditions. The transformer model also supports the case when the 
nominal transformer efficiency is given. In this case, the user needs to provide the nameplate efficiency and the corresponding per unit load, the maximum efficiency and the corresponding per unit load, and the reference conductor temperature at which the nameplate efficiency is measured. Given these information, both no load loss and load loss at rated conditions can be derived as follows.

The nameplate efficiency can be expressed as:

$$
\eta_{n p}=\frac{S_{B} * P_{n p}}{S_{B} * P_{n p}+N L+L L * P_{n p}^{2} * f_{T, n p}}
$$

where,

$$
\begin{array}{ll}
\eta_{n p} & \text { Nameplate efficiency } \\
S_{B} & \text { Nameplate rating (VA) } \\
P_{n p} & \text { Per unit load at which the nameplate efficiency is measured } \\
f_{T, n p} & \quad \text { Applied temperature correction factor for the nameplate efficiency. }
\end{array}
$$

Maximum efficiency generally occurs when the load loss is equal to the no-load loss. Because the no-load loss does not vary with the load on the transformer, the following relationship can be established:

$$
N L=L L_{\max , \eta}=L L * P_{\max , \eta}^{2} * f_{T, \max -\eta}
$$

where,

$$
\begin{aligned}
& P_{\max , \eta} \quad \text { Per unit load at which the maximum efficiency is obtained } \\
& f_{T, \max -\eta} \quad \text { Applied temperature correction factor for the maximum efficiency. }
\end{aligned}
$$

Transformers typically have close per unit loads for the nameplate efficiency and the maximum efficiency. Therefore, it is reasonable to assume that the applied temperature correction factors are equal at those two efficiencies. This implies that:

$$
\frac{L L_{n p}}{L L_{\max , \eta}}=\frac{L L^{*} P_{n p}{ }^{2} * f_{T, n p}}{L L^{*} P_{\max , \eta}{ }^{2} * f_{T, \max -\eta}}=\left(\frac{P_{n p}}{P_{\max , \eta}}\right)^{2}
$$

Rearranging Equation 3.9 and combining it with Equation 3.8 leads to: 


$$
\begin{gathered}
L L_{n p}=L L_{\max , \eta} *\left(\frac{P_{n p}}{P_{\max , \eta}}\right)^{2} \\
=N L *\left(\frac{P_{n p}}{P_{\text {max }, \eta}}\right)^{2}
\end{gathered}
$$

Combining Equations 3.7 and 3.10, we can obtain the no load loss as:

$$
N L=\frac{S_{B} * P_{n p} *\left(1-\eta_{n p}\right)}{\eta_{n p} *\left[1+\left(\frac{P_{r e f}}{P_{\text {max }, \eta}}\right)^{2}\right]}
$$

Substitute NL into Equation 3.8, we can calculate the load loss at rated conditions as:

$$
L L=\frac{N L}{f_{T, \max -\eta} * P_{\max , \eta}^{2}}=\frac{N L}{f_{T, n p} * P_{\max , \eta}^{2}}
$$

Since both no load and load losses at rated conditions are known, the total energy losses in a transformer at time t can then be calculated according to Equation 3.1.

Fortran 90 is the programming language used to implement the transformer model. Efforts were taken during implementation to follow the EnergyPlus programming standard (DOE 2010). The transformer model involves three source code file changes: DataHeatBalance.f90,

HeatBalanceInternalHeatGains.f90, and ElectricPowerManager.f90. The first two files have very minor changes which are made to account for the transformer energy loss as heat gains into a thermal zone, where the transformer is located. In contrast, the last file has most code changes with over 500 lines of source code added or changed in comparison with the previous version.

Figure 3-1 is the flowchart showing how the transformer model is calculated depending on the inputs. After the highest level subroutine (ManageElectricLoadCenters) responsible for all objects in the group of electric load center calls the transformer model (subroutine ManageTransformers), the transformer model checks whether there is a transformer object in the input file. If it is the first simulation time step, the rated losses and nonrated losses need to be calculated if the performance input method is based on nominal efficiency. Depending on the transformer usage mode, the transformer load is calculated either as the sum of wired meters or the sum of surplus power from the served electric load centers. Once the transformer load is obtained, all model outputs can be derived based on the algorithm presented in previous section. 


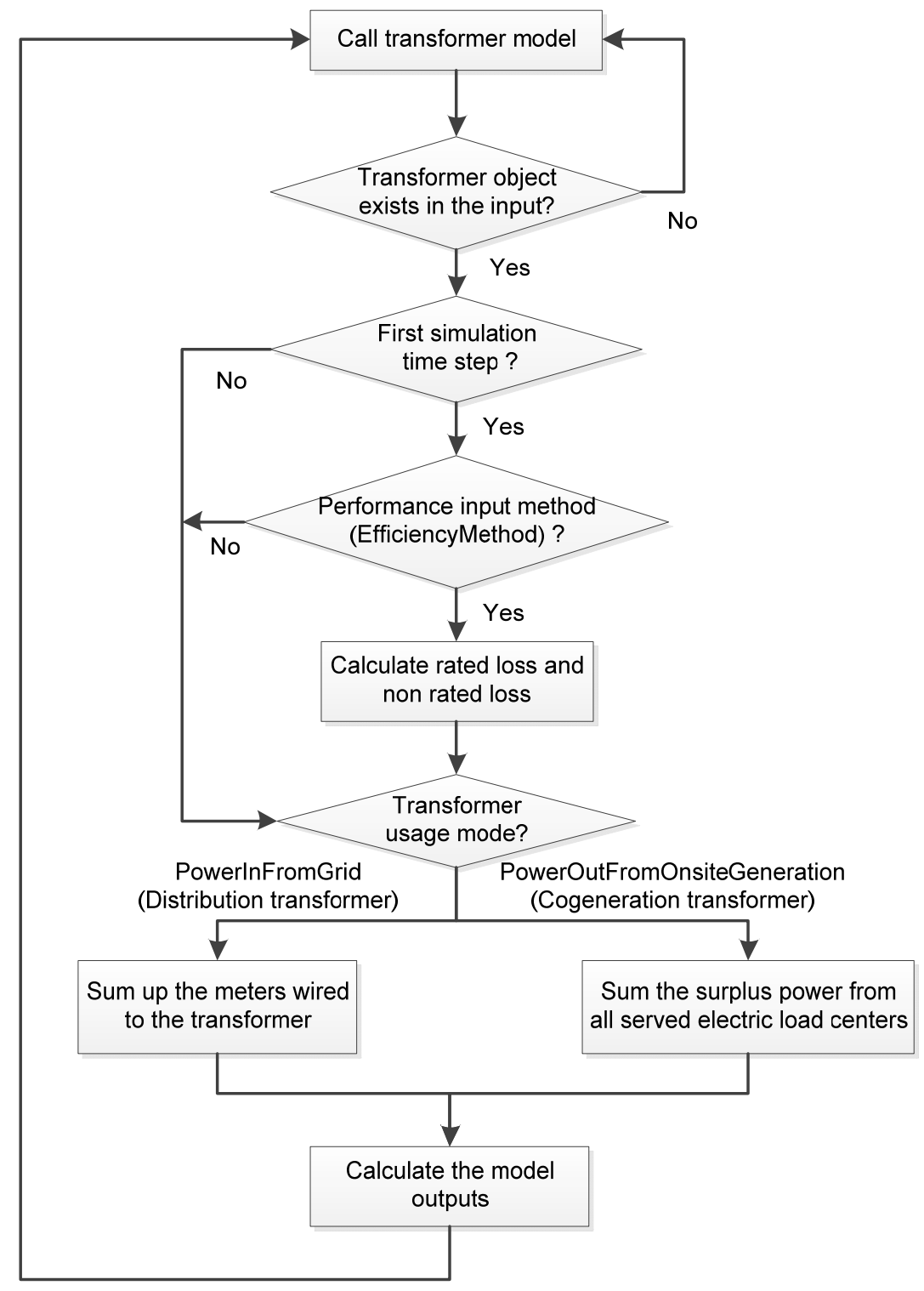

Figure 3-1. Flowchart for the implemented transformer model

\subsection{Descriptions of Input Fields and Output Variables}

Two EnergyPlus objects are changed for the addition of a transformer model into EnergyPlus Version 5.0. First, a brand new object named ElectricLoadCenter:Transformer is added. Second, the existing object named ElectricLoadCenter:Distribution is modified to establish the connection between 
onsite power generation and transformers. In the distribution object, a field is added to specify the transformer object name. In the following subsections, descriptions of input and output variables are introduced.

\subsubsection{Input Fields for Transformer Model}

\section{Field: Availability Schedule Name}

This alpha field contains the schedule name (ref. Schedule) that contains information on the availability of the transformer. A schedule value greater than 0 (usually 1 is used) indicates that the transformer is available to convert AC power from one voltage to another. A value less than or equal to 0 (usually 0 is used) denotes that the transformer is not available.

\section{Field: Transformer Usage}

This field indicates one of the two supported transformer application types: PowerInFromGrid and PowerOutFromOnsiteGeneration. The first type of transformer is used to step down voltage from the electricity grid to a building. The second type of transformer is used to match voltage from building onsite generators to the electricity grid.

\section{Field: Zone Name}

This field contains the name of the thermal zone where the transformer is located. Entering a valid name of zone here will direct EnergyPlus to include the transformer's losses as heat gains to the named thermal zone. If the transformer is not within a thermal zone, this field can be left blank, and the thermal energy associated with transformer losses is removed from the building model.

\section{Field: Radiative Fraction}

This field contains the fraction of transformer's losses that enter the zone as long-wave thermal radiation. This numeric filed should have a value between 0.0 and 1.0. The balance of the losses is convective. This field is not used if the previous field for zone name is left blank.

\section{Field: Rated Capacity}

This field defines the rated capacity of the transformer in VA.

\section{Field: Phase}

This field indicates whether the transformer is a single phase or three phase type. The two alternative values are 1 or 3 . The default is 3 . This field is currently not used in the model. 


\section{Field: Conductor Material}

This field specifies the winding material used by the transformer. There are two options: Copper and Aluminum. The choice will determine the thermal coefficient of resistance used to calculate the temperature correction factor for the transformer load losses. The default is Aluminum.

\section{Field: Full Load Temperature Rise}

This numeric field defines the temperature rise of the windings above the ambient temperature, when the transformer is loaded at its nameplate rating. For liquid-immersed distribution transformers, the full load temperature rise usually takes the value of $65^{\circ} \mathrm{C}$. For dry-type transformers, the temperature rise usually takes three optional values: 80,115 and $150^{\circ} \mathrm{C}$. This field accepts any value between the minimum $\left(50^{\circ} \mathrm{C}\right)$ and the maximum $\left(180^{\circ} \mathrm{C}\right)$. The default is $150^{\circ} \mathrm{C}$.

\section{Field: Fraction of Eddy Current Losses}

This field defines the fraction of load losses resulting from the eddy currents. Transformer's load losses comprise two parts: the ohmic loss due to the current flowing in the resistance of the windings and the eddy and stray losses due to the eddy currents. This field indicates the fraction of the load losses due to the eddy currents. This numeric field should have a value between 0.0 and 1.0. The default is 0.1 .

\section{Field: Performance Input Method}

This alpha field contains the method by which the user will specify the transformer performance: "RatedLosses” or "NominalEfficiency”. If this field is left blank in the input data file, the default input method is assumed to be "RatedLosses". If the method "NominalEfficiency" is selected, the user must enter the fields for the nameplate efficiency and the corresponding reference conditions as described below. If the method "RatedLosses" is selected, then the fields for rated no load loss and load loss must be entered as described below.

\section{Field: Rated No Load Loss}

This field defines the no load loss (W) at rated load and conditions. The no load loss is roughly constant and exists whenever the transformer is energized. The no load loss is also called the core loss. This field is used only if the field of Performance Input Method is specified as "RatedLosses".

\section{Field: Rated Load Loss}

This field defines the load loss (W) at rated load and conditions. The load loss varies with the square of the load being served by the transformer. The load loss is also called the winding loss because the load loss occurs in the primary and secondary windings around the core. This field is used only if the field of Performance Input Method is specified as “RatedLosses”. 


\section{Field: Nameplate Efficiency}

This field contains the value for transformer efficiency at a given per unit load and specified reference temperature. This field is used only if the field of Performance Input Method is specified as “NominalEfficiency”. The default is 0.98 .

\section{Field: Per Unit Load for Nameplate Efficiency}

This field defines the percentage of the rated capacity at which the nameplate efficiency is measured. According to the NEMA (National Electrical Manufacturers Association) Standard TP-1, the per unit load takes the value of 0.35 for dry-type distribution transformers, and it takes the value of 0.50 for liquidfilled distribution transformers. The default is 0.35 .

\section{Field: Reference Temperature for Nameplate Efficiency}

This field defines the conductor temperature at which the nameplate efficiency is measured. This field is used only if the field of Performance Input Method is specified as "NominalEfficiency". According to the NEMA Standard TP-1, the reference temperature takes the value of $75^{\circ} \mathrm{C}$ for dry-type distribution transformers, and it takes the value of $55^{\circ} \mathrm{C}$ for liquid-filled distribution transformers. The default is $75^{\circ} \mathrm{C}$.

\section{Field: Per Unit Load for Maximum Efficiency}

This field defines the percentage of the rated capacity at which the maximum efficiency is obtained. This field is used only if the field of Performance Input Method is specified as "NominalEfficiency". A blank field indicates that it takes the same value as the per unit load for nameplate efficiency.

\section{Field: Consider Transformer Loss for Utility Cost}

This field indicates whether the transformer losses are considered to calculate utility cost. In some cases, the transformer losses are required but they are not part of the energy consumption for utility cost calculation. For example, the transformer is owned by the utility company but it is located in the building. In this case, it might be desired to model transformer energy losses for HVAC operation, but the energy losses will not account for utility cost.

\section{Field: Electric Meter 1-10 Name}

A transformer may serve different loads such as plug loads, some lighting loads, and some HVAC equipment loads. The user needs to specify which loads are connected to the transformer. This is achieved by providing a list of electric meters wired to the transformer. The input object can currently accommodate up to 10 meters, but it is extensible by modifying the Energy+.idd entry. Any valid electric meter name can be used here to wire to the transformer loads. Many different meters are automatically 
generated by the program and will depend on the objects used throughout the input file. The typical process of determining the exact name to enter in this field involves doing an initial run of EnergyPlus and then examining the *.mdd file, which will list the meters and their resulting names. A custom meter is also supported. The meter must have electricity as its resource type.

\subsubsection{Output Variables for Transformer Model}

\section{Transformer Efficiency[]}

This output field is the efficiency at which the distribution transformer changes alternating current from the higher primary voltage to a lower secondary voltage. The efficiency is calculated for each HVAC system timestep being simulated, and the results are averaged for the timestep being reported.

\section{Transformer Power Output[W] and Transformer Energy Output[J]}

These outputs are the total electricity power or energy provided by the transformer. They are equal to the metered loads that are wired to the transformer. These values are calculated for each HVAC system timestep being simulated, and the results are averaged (for power) or summed (for energy) for the timestep being reported.

\section{Transformer Power Input[W] and Transformer Energy Input[J]}

These outputs are the total electricity power or energy fed into the transformer. These values are calculated for each HVAC system timestep being simulated, and the results are averaged (for power) or summed (for energy) for the timestep being reported.

\section{Transformer No Load Loss Rate[W] and Transformer No Load Loss Energy[J]}

These outputs are the no load loss occurred in the transformer. These values are calculated for each HVAC system timestep being simulated, and the results are averaged (for rate) or summed (for energy) for the timestep being reported.

\section{Transformer Load Loss Rate[W] and Transformer Load Loss Energy[J]}

These outputs are the load loss occurred in the transformer. These values are calculated for each HVAC system timestep being simulated, and the results are averaged (for rate) or summed (for energy) for the timestep being reported.

Transformer Thermal Loss Rate[W] and Transformer Thermal Loss Energy[J] 
These outputs are the total energy losses occurred in the transformer. They are equal to the sum of the no load loss and the load loss. These values are calculated for each HVAC system timestep being simulated, and the results are averaged (for rate) or summed (for energy) for the timestep being reported.

\section{Energy Consumption for Distribution Transformer[J]}

This output is the total energy losses occurred in the transformer when it is used for input power from grid to building. It is set as zero if the transformer is used to transfer energy from onsite power generators to the electricity grid. This output is also added to a report meter with ResourceType = Electricity, GroupKey $=$ System.

\section{Energy Consumption for Cogeneration Transformer[J]}

This output is the total energy losses occurred in the transformer when it is used for input onsite cogeneration to the grid. It is set as zero if the transformer is used to transfer electricity from the grid to building. This output is also added to a report meter with ResourceType = ElectricityProduced, EndUseKey $=$ Cogeneration, GroupKey $=$ System .

\subsection{Testing and Verification}

Two available example files from EnergyPlus Version 5 were used to verify that the transformer model had been implemented correctly. One file named 5ZoneAirCooled.idf serves as the starting point to test the transformer model when it is used to transform power from grid to building. The other file named Generators.idf serves as the starting point to test the transformer model when it is used to transfer power from onsite generation to the electricity grid. The following major steps are used in the verification process.

Step 1: The output variables are modified in the original example files to obtain the interested outputs (e.g., Electricity:Building meter value at each time step) when the transformer is not used.

Step 2: A spreadsheet table is created with the applicable EnergyPlus outputs as the transformer load. The transformer losses are calculated for each time step according to the algorithm presented in Section 2.

Step 3: A transformer is added to each of the two original EnergyPlus input files. The models with an added transformer object are run with all transformer output variables reported.

Step 4: The transformer losses from the spreadsheet calculation in Step 2 and the EnergyPlus output from Step 3 are compared to make sure they match with each other. 
Step 5: The affected meter outputs due to transformer losses are examined to make sure that they are changed correctly. For example, after adding the distribution transformer, the meter outputs from Electricity:HVAC and Electricity:Facility should be increased by the same amount of transformer losses.

Both tests demonstrated that the transformer model was implemented correctly. The two test files with transformer objects will be included in the example files for EnergyPlus Version 6.0.

\subsection{References}

Barnes, PR, JW Van Dyke, BW McConnell, and S. Das. 1996. Determination Analysis of Energy Conservation Standards for Distribution Transformer, ORNL-6847. Oak Ridge National Laboratory, Oak Ridge, TN.

Barnes, PR, S Das, BW McConnell, and JW Van Dyke. 1997. Supplement to the "Determination Analysis” (ORNL-6847) and Analysis of the NEMA Efficiency Standard for Distribution Transformer, ORNL-6925. Oak Ridge National Laboratory, Oak Ridge, TN.

DOE. 2010. EnergyPlus Documentation. U.S. Department of Energy.

NEMA. 2002. NEMA Standards Publication TP 1-2002: Guide for Determining Energy Efficiency for Distribution Transformers. National Electrical Manufacturers Association, Rosslyn, VA. 


\section{Development of Life-Cycle Costing Features}

Life-cycle costing is used with building energy simulation to justify energy efficiency upgrades. Many alterative building technologies that result in energy savings cost more initially, or may cost more to maintain, than traditional solutions. To justify selecting these energy savings technologies, it is essential to combine both initial and future costs in the decision process. Using life-cycle costs provides a framework to combine initial costs and future costs into a single combined measure, called the "present value.” Present value is a metric that combines all costs and reduces (or discounts) those costs that occur in the future. Discounting future costs is based on the principal of the time value of money.

An approach used to model the life-cycle costing feature is presented in Section 4.1. A description of each input field in the life-cycle costing model is provided in Section 4.2. A verification of model performance is presented in Section 4.3.

\subsection{Approach}

The calculations are based on discounting the future values according to normal life-cycle costing techniques as described in NIST Handbook 135 (Fuller and Petersen, 1995).

The following is a list of life-cycle costing related objects that provide a way to describe the parameters and costs associated with the life-cycle of a building or building system:

- LifeCycleCost:Parameters

- LifeCycleCost:RecurringCosts

- LifeCycleCost:NonrecurringCost

- LifeCycleCost:UsePriceEscalation

- LifeCycleCost:UseAdjustment.

The utility costs (see UtilityCost:Tariff) and first costs (see ComponentCost:LineItem) are calculated by EnergyPlus and used along with other current and future costs input using the LifeCycleCost:RecurringCosts and LifeCycleCost:NonrecurringCost objects. These are combined into the present value life-cycle cost metric. The LifeCycleCost:Parameters object establishes the set of assumptions for the analysis along with LifeCycleCost:UsePriceEscalation (often from a DataSet) and LifeCycleCost:UseAdjustment. It is important to understand that the comparison of different simulation results and their present values is not performed by EnergyPlus. Instead, EnergyPlus provides the present 
value calculations for a specific simulation combining the energy costs, first costs, and future costs, and you need to make the comparison between the results of multiple simulations.

The results of using the LifeCycleCost objects are included automatically in the tabular report file whenever the LifeCycleCost:Parameters object is present. The report appearing in the tabular report file is titled "Life Cycle Cost Report." This report shows the costs and the timing of costs, often called "cash flows," along with the present value in several different tables. The tabular results would show the present value of all current and future costs.

The datasets file, LCCusePriceEscalationDataSet2010.idf, includes the energy escalation factors from the NIST Handbook 135 annual supplement as of 2010. These are necessary because the expected change in price for electricity and various fuels does not change at the same rate as inflation.

Life-cycle costing should not be confused with life-cycle analysis. With life-cycle costing, the result is an economic evaluation of current and future expenditures to make a decision on alternative investments. In life-cycle analysis, the environmental impact such as equivalent $\mathrm{CO}_{2}$ production involved in the materials, delivery, manufacturing, and construction are combined with environmental impacts of the building in operation and the eventual removal of the building, and is used to understand the overall environmental impact or embodied energy.

The computation of life-cycle costs is broken into three main routines, which are described below.

\section{ExpressAsCashFlows}

Step 1. If the input file has ComponentCost:* items, then create an additional instance of a nonrecurring cost to hold the total.

Step 2. Get the costs for each resource that has non-zero utility costs.

Step 3. Compute the inflation on a monthly basis. For cases where the inflation approach is constant dollars, the inflation is set to 1.0 for all months. For current dollar analyses, compute the inflation rate on a monthly basis. Just using 1/12 of the annual inflation is almost correct but introduces a small error. Instead the inverse of the formula 4-32 from Newnan et al. (2004):

$$
\text { inflationPerMonth }=((\text { inflation }+1.00) * *(1.0 / 12.0))-1
$$


Then the inflation is applied for each month:

$$
\text { monthlyInflationFactor(jMonth) }=(1+\text { inflationPerMonth }) * *(j M o n t h-1)
$$

Step 4. Put the nonrecurring, nonrecurring, and utility costs into a monthly array for the entire length of the study period.

Step 5. Multiply the monthly costs by the monthly inflation, which was set to 1.0 for constant dollar analyses.

Step 6. Multiply the monthly costs for resources with use adjustments.

Step 7. Sum the monthly costs by category.

Step 8. Based on the base date, accumulate the monthly costs into yearly costs.

\section{ComputePresentValue}

Step 1. For each year of the study, compute the discount factor (SPV) using the following formula:

$$
\text { SPVyr }=1 /((1+\text { curDiscountRate }) * * \text { effectiveYear })
$$

This formula is based on formula D.2.1.1 from NIST Handbook 135 (Fuller and Petersen, 1995). Where the effectiveYear depends on the discount convention. If end of year discounting is used, then the effectiveYear is the year. If middle of the year discounting is used, then the effectiveYear is reduced by 0.5. If the beginning of year discounting is used, then the effectiveYear is reduced by 1.0. For energy costs, the use price escalations are multiplied by the discount factors.

Step 2. Compute the present value for each month by multiplying the monthly costs by the discount factor for each year.

Step 3. Sum the costs by category.

\section{ComputeTaxAndDepreciation}

Step 1. Depending on the depreciation method selected, the depreciation factors are set to various constants. Depreciation factors are based on IRS Publication 946 for 2009 "How to Depreciate Property." The Modified Accelerated Cost Recovery System (MACRS) values are based on 
MACRS GDS for 3, 5, 7, 10 year property are based on 200\% depreciation method shown in Appendix A of IRS Publication 946 using half year. 15 and 20 years are based on 150\% (Chart 1 of IRS Publication 946). For Straight Line depreciation GDS is used for 27 years (actually 27.5) 31 years (actually 31.5 years) and 39 years using mid month. For 40 years ADS is used (chart 2) Table A-1 is used for 3, 4, 5, 10, 15 and 20 years. Table A-6 is for 27 years. Table A-7 for 31 years. Table A-7a for 39 years. Table A-13 for 40 years. These years are a classification of property and should not be confused with the length of the study. For 27 years, 31 years, 39 years and 40 years the June value was used. All references in this paragraph are to IRS Publication 946.

Step 2. Apply the annual depreciation factors to the capital costs.

Step 3. For each year the taxable income is the grand total of all costs minus the depreciated capital costs.

Step 4. Taxes are the taxable income times the tax rate.

Step 5. The after tax present value is

$$
\text { AfterTaxPresentValueyr }=\text { GrandTotalyr }- \text { Taxesyr } * \text { SPVyr }
$$

All major results are presented on the tabular report.

\subsection{Descriptions of Input Fields}

In Section 4.1, a list of life-cycle costing related objects was introduced. The input variables for each object are described in the following subsections.

\subsubsection{Input Fields for LifeCycleCost:Parameters}

This object provides inputs related to the overall life-cycle analysis. It establishes many of the assumptions used in computing the present value. It is important that when comparing the results of multiple simulations, fields in the LifeCycleCost:Parameters objects are the same for all the simulations. To aid in this comparison, the first table in the Life-Cycle Cost Report shows the inputs to this object. Only one LifeCycleCost:Parameters object is permitted for a file. When this object is present the tabular report file will contain the Life-Cycle Cost Report.

\section{Field: Name}

An identifying name used for the LifeCycleCost:Parameters object. 


\section{Field: Discounting Convention}

The field specifies if the discounting of future costs should be computed as occurring at the end of each year, the middle of each year, or the beginning of each year. The most common discounting convention uses the end of each year. Without a specific reason, the end of each year should be used. Some military projects may specifically require using the middle of each year. The year being used starts with the base year and month, and repeats every full year. All costs assumed to occur during that duration are accumulated and shown as an expense either at the beginning, middle or end of the year. The options are:

- BeginningOfYear

- $\quad$ MidYear

- EndOfYear.

\section{Field: Inflation Approach}

This field is used to determine if the analysis should use constant dollars or current dollars, which is related to how inflation is treated. The two options are:

- ConstantDollar

- CurrentDollar .

The default option is ConstantDollars. If ConstantDollar is selected, then the Real Discount Rate input is used and it excludes the rate of inflation. If CurrentDollar is selected, then the Nominal Discount Rate input is used and it includes the rate of inflation. From NIST Handbook 135: "The constant dollar approach has the advantage of avoiding the need to project future rates of inflation or deflation. The price of a good or service stated in constant dollars is not affected by the rate of general inflation. For example, if the price of a piece of equipment is $\$ 1,000$ today and $\$ 1,050$ at the end of a year in which prices in general have risen at an annual rate of 5 percent, the price stated in constant dollars is still $\$ 1,000$; no inflation adjustment is necessary. In contrast, if cash flows are stated in current dollars, future amounts include general inflation, and an adjustment is necessary to convert the current-dollar estimate to its constant-dollar equivalent. This adjustment is important because constant- and current-dollar amounts must not be combined in an LCCA [life-cycle cost analysis].” For most analyses, using the ConstantDollar option will be easier since the effect of inflation may be ignored.

\section{Field: Real Discount Rate}

Enter the Real Discount Rate as a decimal. For a 3\% rate, enter the value 0.03. This input is used when the Inflation Approach is ConstantDollar. The real discount rate reflects the interest rates needed to make current and future expenditures have comparable equivalent values when general inflation is ignored. 
When Inflation Approach is set to CurrentDollar this input is ignored. If this field is blank and Inflation Approach is ConstantDollar, a warning is issued.

\section{Field: Nominal Discount Rate}

Enter the nominal discount rate as a decimal. For a 5\% rate, enter the value 0.05 . This input is used when the Inflation Approach is CurrentDollar. The real discount rate reflects the interest rates needed to make current and future expenditures have comparable equivalent values when general inflation is included. When Inflation Approach is set to ConstantDollar this input is ignored. If this field is blank and Inflation Approach is CurrentDollar, a warning is issued.

\section{Field: Inflation Rate}

Enter the rate of inflation for general goods and services as a decimal. For a $2 \%$ rate, enter the value 0.02 . If this field is not blank and Inflation Approach is ConstantDollar, a warning is issued.

\section{Field: Base Date Month}

Enter the month that is the beginning of study period, also known as the beginning of the base period. According to NIST 135 "the base date is the point in time to which all project-related costs are discounted in an LCCA [life cycle cost analysis]. The base date is usually the first day of the study period for the project, which in turn is usually the date that the LCCA is performed. In a constant-dollar analysis, the base date usually defines the time reference for the constant dollars (e.g., 1995 constant dollars). It is essential that you use the same base data and constant-dollar year for all of the project alternatives to be compared. If you set the base date to the date that the LCCA is performed, then the constant-dollar basis for the analysis will be the current date, and you can use actual costs as of that date without adjusting for general inflation.” The choices are:

- January

- February

- March

- April

- May

- June

- July

- August

- September

- October 
- November

- December.

The default value is January. This field could also be referred to as part of "the date of study.” It is used as the date for constant dollars.

\section{Field: Base Date Year}

Enter the four digit year that is the beginning of study period, such as 2010. The study period is also known as the base period. See more details in the previous field.

\section{Field: Service Date Month}

Enter the month that is the beginning of building occupancy. Energy costs computed by EnergyPlus are assumed to occur during the year following the service date. The service date must be the same or later than the Base Date. The choices are:

- January

- February

- March

- April

- May

- June

- July

- August

- September

- October

- November

- December .

The default value is January. According to NIST Handbook 135: "The service date is the date on which the project is expected to be implemented; operating and maintenance costs (including energy- and waterrelated costs) are generally incurred after this date, not before.” This field could also be referred to as part of "beneficial occupancy date."

\section{Field: Service Date Year}

Enter the four digit year that is the beginning of occupancy, such as 2010. See more details in the previous field. 


\section{Field: Length of Study Period in Years}

Enter the number of years of the study period. It is the number of years that the study continues based on the start at the base date. The default value is 25 years. Only integers may be used indicating whole years. According to NIST Handbook 135, "the study period for an LCCA is the time over which the costs and benefits related to a capital investment decision are of interest to the decision maker. Thus, the study period begins with the base date and includes both the [planning/construction] period (if any) and the relevant service period for the project. The service period begins with the service date and extends to the end of the study period.”

\section{Field: Tax rate}

Enter the overall marginal tax rate for the project costs. This does not include energy or water taxes. The single tax rate entered here is not intended to be a replacement of the complex calculations necessary to compute personal or corporate taxes; instead it is an approximation that may be used for a simple analysis assuming a constant tax rate is applied on all costs. The tax rate entered should be based on the marginal tax rate for the entity and not the average tax rate. Enter the tax rate results in present value calculations after taxes. Most analyses do not factor in the impact of taxes and assume that all options under consideration have roughly the same tax impact. Due to this, many times the tax rate can be left to default to zero and the present value results before taxes are used to make decisions. The value should be entered as a decimal value. For $15 \%$ enter 0.15 . For an analysis that does not include tax impacts, enter 0.0 . The default is 0 .

\section{Field: Depreciation Method}

For an analysis that includes income tax impacts, this entry describes how capital costs are depreciated. According to IRS Publication 946 - How to Depreciate Property "Depreciation is an annual income tax deduction that allows you to recover the cost or other basis of certain property over the time you use the property. It is an allowance for fair market value of the wear and tear, deterioration, or obsolescence of the Intangible property.” Details on which depreciation method to choose depends on the property being depreciated and IRS Publication 946 and your accountant are the best sources of information in determining which depreciation method to choose. Only one depreciation method may be used for an analysis and is applied to all capital expenditures. Only analyses that include tax impacts need to select a depreciation method. The options are:

- ModifiedAcceleratedCostRecoverySystem-3year

- ModifiedAcceleratedCostRecoverySystem-5year

- ModifiedAcceleratedCostRecoverySystem-7year 
- ModifiedAcceleratedCostRecoverySystem-10year

- ModifiedAcceleratedCostRecoverySystem-15year

- ModifiedAcceleratedCostRecoverySystem-20year

- StraightLine-27year

- StraightLine-31year

- $\quad$ StraightLine-39year

- StraightLine-40year.

No depreciation allowances reduce the actual/nominal tax dollars paid by the owner. Thus, analyses using depreciation should be conducted in nominal dollars. For an analysis that does not include tax effects, None should be selected. The default value is None.

\subsubsection{Input Fields for LifeCycleCost:RecurringCosts}

Recurring costs are costs that repeat over time on a regular schedule during the study period. If costs associated with equipment do repeat but not on a regular schedule, use LifeCycleCost:NonrecurringCost objects instead.

\section{Field: Name}

The identifier used for the object. The name is used in identifying the cash flow equivalent in the output results in the Life-Cycle Cost Report.

\section{Field: Category}

Enter the category of the recurring costs. Choose the closest category. The options include:

- EnergyCosts

- WaterCosts

- Maintenance

- Repair

- Operation

- Replacement

- MinorOverhaul

- MajorOverhaul

- OtherOperational. 
The default value is Maintenance. For recommendations on estimating other operational costs, see NIST 135 Section 4.6.3.

\section{Field: Cost}

Enter the cost in dollars (or the appropriate monetary unit) for the recurring costs. Enter the cost for each time it occurs. For example, if the annual maintenance cost is $\$ 500$, enter 500 here.

\section{Field: Start of Costs}

Enter when the costs start. The First Year of Cost is based on the number of years past the Start of Costs. For most maintenance costs, the Start of Costs should be Service Period. The options are:

- $\quad$ ServicePeriod

- BasePeriod.

The default value is ServicePeriod.

\section{Field: Years From Start}

This field and the Months From Start field together represent the time from either the start of the Service Period, on the service month and year, or start of the Base Period, on the base month and year (depending on the Start of Costs field) that the costs start to occur. Normally, for most maintenance costs that begin in the first year that the equipment is in service the Start of Costs is the Service Period and the Years from Start will be 0 . Only integers should be entered representing whole years. The default value is 0 .

\section{Field: Months From Start}

This field and the Years From Start field together represent the time from either the start of the Service Period, on the service month and year, or start of the Base Period, on the base month and year (depending on the Start of Costs field) that the costs start to occur. Normally, for most maintenance costs the Start of Costs is the Service Period and the Months from Start will be 0. Only integers should be entered representing whole months. The Years From Start (times 12) and Months From Start are added together. The default value is 0 .

\section{Field: Repeat Period Years}

This field and the Repeat Period Months field indicate how much time elapses between reoccurrences of the cost. For costs that occur every year, such as annual maintenance costs, the Repeat Period Years 
should be 1 and Repeat Period Months should be 0 . Only integers should be entered representing whole years. The default value is 1 .

\section{Field: Repeat Period Months}

This field and the Repeat Period Years field indicate how much time elapses between reoccurrences of the cost. For costs that occur every year the Repeat Period Years should be 1 and Repeat Period Months should be 0 . For, costs that occur every eighteen months, the Repeat Period Years should be 1 and the Repeat Period Months should be 6. Only integers should be entered representing whole years. The Repeat Period Years (times 12) and Repeat Period Months are added together. The default value is 0.

\section{Field: Annual Escalation Rate}

Enter the annual escalation rate as a decimal. For a $1 \%$ rate, enter the value 0.01 . This input is used when the Inflation Approach is CurrentDollar. When Inflation Approach is set to ConstantDollar this input is ignored. The default value is 0 .

\subsubsection{Input Fields for LifeCycleCost:NonrecurringCost}

A non-recurring cost happens only once during the study period. For costs that occur more than once during the study period on a regular schedule, use the LifeCycleCost:RecurringCost object.

\section{Field: Name}

The identifier used for the object. The name is used in identifying the cash flow equivalent in the output results in the Life-Cycle Cost Report.

\section{Field: Category}

Enter the category of the non-recurring costs. Choose the closest category. The options include:

- Construction

- Salvage

- OtherCapital.

The default is Construction. For recommendations on estimating capital and salvage (residual) costs, see NIST 135 Section 4.5. 


\section{Field: Cost}

Enter the non-recurring cost value. For Construction and other capital costs the value entered is typically a positive value. For Salvage costs, the value entered is typically a negative value which represents the money paid to the investor for the equipment at the end of the study period.

\section{Field: Start of Costs}

Enter when the costs start. The First Year of Cost is based on the number of years past the Start of Costs. For most non-recurring costs the Start of Costs should be Base Period, which begins at the base month and year. The options are:

- ServicePeriod

- BasePeriod.

The default value is BasePeriod

\section{Field: Years From Start}

This field and the Months From Start field together represent the time from either the start of the Service Period, on the service month and year, or start of the Base Period, on the base month and year (depending on the Start of Cost field) that the costs start to occur. Normally, for most capital costs the Start of Costs is the Base Period and the Years from Start will be 0. These would be first costs for the building equipment or system. Salvage costs are usually shown as happening in the last year of the analysis. Only integers should be entered representing whole years. The default value is 0 .

\section{Field: Months From Start}

This field and the Years From Start field together represent the time from either the start of the Service Period, on the service month and year, or start of the Base Period, on the base month and year (depending on the Start of Cost field) that the costs start to occur. Normally, for most capital costs the Start of Costs is the Base Period and the Months from Start will be 0. Only integers should be entered representing whole months. The Years From Start (times 12) and Months From Start are added together. The default value is 0 .

\subsubsection{Input Fields for LifeCycleCost:UsePriceEscalation}

The LifeCycleCost:UsePriceEscalation object will commonly be part of a dataset on life-cycle costs. The values for this object may be found in the annual supplement to NIST Handbook 135 in Tables Ca-1 to Ca-5. A dataset file comes with EnergyPlus in the DataSet directory and includes the LCCusePriceEscalationDataSet2010.idf file which includes the value for the 2010 supplement to NIST 
135. The object provides inputs for the escalations of energy and water costs assuming that they change differently than inflation. According to the NIST 135 supplement the values are "present projected fuel price indices for the four Census regions and for the United States. These indices, when multiplied by annual energy costs computed at base-date prices (i.e., as of April 1, 2010), provide estimates of futureyear costs (also as of April 1) in constant base-date dollars. Constant-dollar cost estimates are needed when discounting is performed with a real discount rate (i.e., a rate that does not include general price inflation)."

\section{Field: Name}

The identifier used for the object. The name usually identifies the location (such as the state, region, country or census area) that the escalations apply to. In addition the name should identify the building class such as residential, commercial, or industrial and the use type such as electricity, natural gas, or water.

\section{Field: Resource}

Enter the resource such as:

- Electricity

- FuelOil\#1

- NaturalGas

- PropaneGas

- FuelOil\#2

- Coal

- Steam

- Gasoline

- Diesel

- Water.

\section{Field: Escalation Start Year}

This field and the Escalation Start Month define the time that corresponds to "Year 1 Escalation" such as 2010, when the escalation rates are applied. This field and the Escalation Start Month define the time that escalation begins. 


\section{Field: Escalation Start Month}

This field and the Escalation Start Year define the time that corresponds to "Year 1 Escalation" such as 2010, when the escalation rates are applied. This field and the Escalation Start Year define the time that escalation begins.

The choices are:

- January

- February

- March

- April

- May

- June

- July

- August

- September

- October

- November

- December.

The default value is January.

\section{Field: Year 1 Escalation}

The escalation in price of the energy or water use for the first year expressed as a decimal.

\section{Field: Year n Escalation}

The escalation in price of the energy or water use for the n-th year expressed as a decimal.

This object is extensible and often includes 25 to 50 years of projected values. If the number of years in LifeCycleCost:UsePriceEscalation is less than the number of years in the analysis period, the remaining years will assume no escalation. Normal inflation will be the only effect for these years.

\subsubsection{Input Fields for LifeCycleCost:UseAdjustment}

This object is used by advanced users to adjust the energy or water use costs for future years. This should not be used for compensating for inflation but should only be used to increase the costs of energy or water based on assumed changes to the actual use of water or energy, such as changes in the future 
function of the building or the impact of future adjacent buildings on energy use. This object is not commonly used and should be used with caution. The adjustments begin at the start of the service period.

\section{Field: Name}

The identifier used for the object.

\section{Field: Resource}

Enter the resource such as:

- Electricity

- NaturalGas

- Steam

- Gasoline

- Diesel

- Coal

- $\quad$ FuelOil \#1

- $\quad$ FuelOil \#2

- Propane

- Water.

\section{Field: Year 1 multiplier}

The multiplier to be applied to the end use cost for the first year in the service period. The total utility costs for the selected end use is multiplied by this value. For no change, enter 1.0.

\section{Field: Year N multiplier}

The multiplier to be applied to the end use cost for each following year. The total utility costs for the selected end use is multiplied by this value. For no change, enter 1.0. This object is extensible and often includes 25 to 50 years of values.

\subsection{Testing and Verification}

An example file named 5ZoneEconomicstariffAndLifeCycleCosts.idf was developed, and used for testing and verification of the EnergyPlus calculations with BLCC5 analysis. Identical inputs were used in both programs, and the results compared for the following four cases:

1. Calculation with EndOfYear, CurrentDollar

2. Calculation with MidYear, ConstantDollar 
3. Calculation with EndOfYear, ConstantDollar

4. Calculation with MidYear, CurrentDollar.

Each case included components with operation and replacement costs, expected life, discount rate, escalation rate recurring and non-recurring costs. The results from testing indicated that deviation in Recurring Cost Cash Flow calculated by both programs was less than 1.5\% in all four cases; deviation in Energy Cost Cash Flow was found to be less 8\%; deviation in Non-Recurring Cost Cash Flow was less than 3\% and Present Value calculations were within 5\%.

\subsection{References}

Fuller, SK and SR Petersen, 1995, Life-Cycle Costing Manual for the Federal Energy Management

Program, NIST, Washington, DC. Available at: http://www.fire.nist.gov/bfrlpubs/build96/art121.html

Newnan, D, T Eschenbach, and J Lavelle. 2004. Engineering Economic Analysis, $9^{\text {th }}$ ed. Oxford University Press, New York, NY. 


\section{Development of an Electric Battery Model}

Distributed onsite power generation in buildings is one potential technological solution to achieve the net-zero energy building design goal. Representative technologies include micro-cogeneration and building-integrated PVs and wind turbines. Because of the inherent temporal mismatch between electrical production and consumption at the building level, electrical storage is an important component in distributed power systems. In addition, with the increasing attention to electricity grid and building interactions, such as demand response technology, electrical storage modeling is expected to be used more often by EnergyPlus users. However, EnergyPlus Version 6.0 only offers a very simple electrical storage model named ElectricLoadCenter:Storage:Simple. This is a simple "bucket" model for electrical storage because it involves basic accounting of the energy flows and losses to determine the state of charge (SOC) over time. This simple model does not represent any of the characteristics of a real secondary battery, such as the voltage-current relationship and the change of usable capacity with SOC. All these limitations make it necessary to develop a more accurate battery model in EnergyPlus

An approach used to model the electric battery is presented in Section 5.1. Descriptions of input and output variables in the proposed transformer model are provided in Section 5.2. A verification of model performance is presented in Section 5.3.

\subsection{Approach}

A battery is a device that involves a conversion between chemical energy and electrical energy by means of electrochemical reactions. A battery consists of one or more electrochemical cells electrically connected in series to form a unit called a battery module. In field applications, a number of battery modules may be connected in parallel and series as a battery bank to provide the required voltage and storage capacity.

A wide variety of battery models are available in literature. These models can be grouped into three classes: electrochemical models, electrical circuit models, and mathematical models. Electrochemical models are usually based on the fundamental chemical processes that occur when the battery is in power charging and discharging. The electrochemical models are not suitable in the context of building simulation because they are complex and many inputs are elusive to most EnergyPlus users. Electrical circuit models are electrical equivalent models using a combination of voltage sources, resistors, and capacitors to depict battery behavior. Mathematical models usually employ empirical equations to describe the battery at a higher level of abstraction than the other two categories of models. Although the 
mathematical models require a number of regression coefficients for empirical equations, they are simple to use and are suitable for building simulations.

A literature review was made on battery models implemented in other building simulation programs such as TRNSYS and ESP-r and the battery models developed outside of the building field. Based on the model capability, the required number of input parameters, the model validation, and the supported battery types, the battery model used in Hybrid2 (Manwell et al. 2006) was selected as the most appropriate one for this work.

Hybrid2 uses the Kinetic Battery Model (KiBaM) originally developed by Manwell and McGowan (1993). With some simplifications, the model was incorporated into the software HOMER as the electrical storage module for distributed power systems. In 2005, KiBaM was implemented as a standalone application in support of the European Union Benchmarking research project (Bindner et al. 2005).

The Kinetic Battery Model assumes that the battery charge is distributed over two tanks: an available-charge tank and a bound-charge tank. The tank for available charges can supply electrons directly to the load, whereas the tank for chemically bound charges can only supply electrons to the available-charge tank. At any time, the total charge $q$ in the battery is the sum of the available charge $\left(q_{1}\right)$ and bound charge $\left(q_{2}\right)$. That is:

$$
q=q_{1}+q_{2}
$$

Based on the governing equations on the change of charge in both tanks (Manwell and McGowan 1993), the battery capacity can be related to a constant charge/discharge current ( $I$ ) as the following equation:

$$
q_{\max }(I)=\frac{q_{\max } k \cdot c \cdot t}{1-e^{-k t}+c\left(k t-1+e^{-k t}\right)}
$$

where,

$$
q_{\max }(I): \text { Maximum capacity (Ah) at charge or discharge current I }
$$

$q_{\max } \quad$ : Maximum capacity (Ah) at infinitesimal current

$t \quad$ : Charge or discharge time (hr), defined by $t=\frac{q_{\max }(I)}{I}$

$k \quad$ : Constant coefficient $\left(\mathrm{hr}^{-1}\right)$

C : Parameter indicating the ratio of available charge capacity to total capacity 
Assuming that a constant current is used in any time step for charging and discharging, the available charge $\left(q_{1}\right)$ and bound charge $\left(q_{2}\right)$ at any time step are given by:

$$
\begin{aligned}
& q_{1}=q_{1,0} e^{-k \Delta t}+\frac{\left(q_{0} k c-I\right)\left(1-e^{-k \Delta t}\right)}{k}-\frac{I c\left(k \Delta t-1+e^{-k \Delta t}\right)}{k} \\
& q_{2}=q_{2,0} e^{-k \Delta t}+q_{0}(1-c)\left(1-e^{-k \Delta t}\right)-\frac{I(1-c)\left(k \Delta t-1+e^{-k \Delta t}\right)}{k}
\end{aligned}
$$

where,

$q_{1,0}:$ Available charge at the beginning of time step (Ah)

$q_{2,0}:$ Bound charge at the beginning of time step (Ah)

$q_{0}$ : Total charge at the beginning of time step (Ah), $q_{0}=q_{1,0}+q_{2,0}$

$\Delta t \quad$ : Length of time step (hr)

KiBaM views the battery as a voltage source in series with an electric resistance (Figure 5-1). The internal resistance is assumed to be constant and the open circuit voltage varies with current and state of charge.

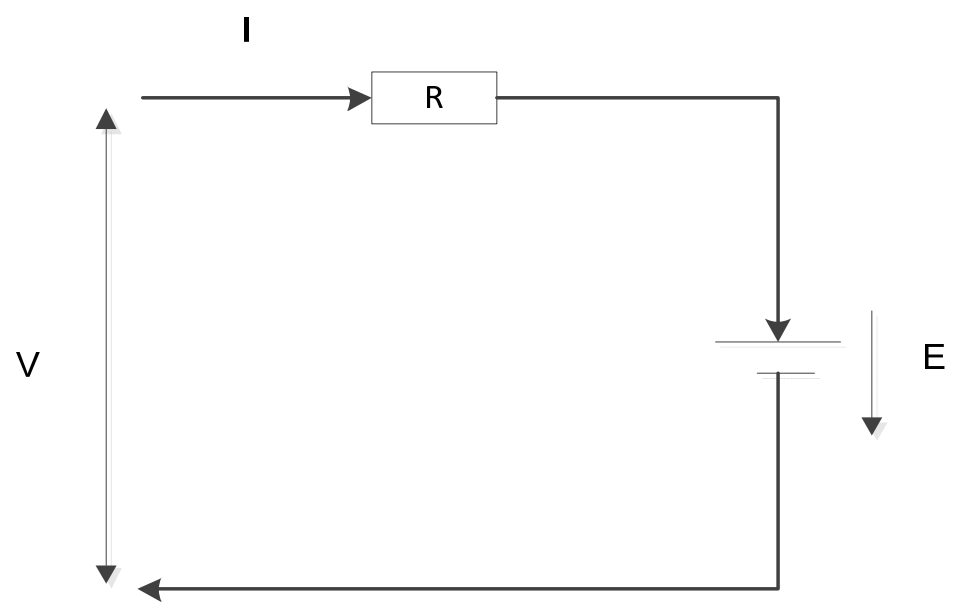

Figure 5-1: Electrical equivalent model for KiBaM 
The battery's open circuit voltage is modeled in the same form for charging and discharging, but with different coefficients. The open circuit voltage in charging $\left(E_{c}\right)$ and in discharging $\left(E_{d}\right)$ can be respectively expressed as:

$$
\begin{aligned}
& E_{c}=E_{0, d}+A_{c} X_{c}+\frac{C_{c} X_{c}}{D_{c}-X_{c}} \\
& E_{d}=E_{0, c}+A_{d} X_{d}+\frac{C_{d} X_{d}}{D_{d}-X_{d}}
\end{aligned}
$$

where,

$$
\begin{array}{ll}
E_{0, c} & : \text { Open circuit voltage for a fully charged battery } \\
E_{0, d} & : \text { Open circuit voltage for a fully discharged battery } \\
A_{c}, C_{c}, D_{c} & : \text { Constant parameters for charging } \\
A_{d}, C_{d}, D_{d} & : \text { Constant parameters for discharging } \\
X_{c}, X_{d} \quad: \text { Normalized maximum capacity at a given charging or discharging current, } & \text { calculated as: }
\end{array}
$$

$$
X= \begin{cases}q_{0} / q_{\max }(I) & (\text { charging }) \\ \left(q_{\max }-q_{0}\right) / q_{\max }(I) & \text { (discharging) }\end{cases}
$$

It needs to be noted that the performance curve (Curve:RectangularHyperbola2) used in the model input covers the $2^{\text {nd }}$ and the $3^{\text {rd }}$ item of the open circuit voltage equation. Due to the reformatting of performance curve, the voltage function regression coefficients can map to the curve coefficients as follows:

$$
C_{1}=-C ; C_{2}=-D ; C_{3}=A
$$

With open circuit voltage, the battery terminal voltage (V) can be calculated as:

$$
V=E-I R
$$

where, R is the battery internal resistance in Ohms and the current $I$ is positive for discharging and negative for charging. 
Given desired power in/out of the battery, the desired charge or discharge current can be calculated from the basic power equation: $P=V I$. In this calculation, iteration is needed to ensure the electric current has converged and the battery operation satisfies all specified technical constraints, such as maximum discharge current and charge rate limit.

$\mathrm{KiBaM}$ assumes that battery life is a primary function of charge/discharge cycles. One cycle is defined as the process of starting from a certain state of charge (SOC), the battery is discharged to a lower SOC and then recharged back to the starting SOC. It is regarded that the magnitude of cycle plays more important than the average of SOC during the cycle. This means that in terms of the impact on battery life, the cycle from $90 \%$ to $70 \%$ and then recharge back to $90 \%$ of SOC is equivalent to another cycle from $50 \%$ to $30 \%$ and then recharge back to $50 \%$ of SOC. Battery life in terms of the number of cycles is predicted as a function of the cycle range measured by the fractional depth of discharge. A double exponential equation is used to capture the damage to batteries due to cycling. The equation takes the following form where the coefficients need to be derived from battery test data via curve fitting.

$$
C_{F}=C_{1}+C_{2} e^{C_{3} R}+C_{4} e^{C_{5} R}
$$

where,

$$
\begin{array}{ll}
C_{F} & : \text { Cycles to failure } \\
C_{1}-C_{5} & : \text { Regression coefficients } \\
\mathrm{R} & \text { : Cycle range in terms of fractional SOC }
\end{array}
$$

Following Hybrid2, the rainflow counting method (Downing and Socie 1982) is used to count battery cycles within a state of charge time series. Based on the number of cycles for each fractional SOC range, the battery damage is estimated as:

$$
D=\sum_{i=1}\left(N_{i} \frac{1}{C_{F, i}}\right)
$$

where,

D : Fractional battery damage. For example, a value of 0.5 at the end of simulation means that half of the battery life is used up after the length of the simulation period.

$C_{F, i}$ : Number of cycles to failure for the i-th cycle range

$N_{i}$ : Total number of cycles over the simulation with the i-th cycle range 
It needs to be noted that the temperature effects on battery performance and battery self-discharge are not supported in the current model.

\subsection{Descriptions of Input Fields and Output Variables}

\subsubsection{Input Fields for ElectricLoadCenter:Storage:Battery}

This object uses the kinetic battery model (KiBaM) to simulate rechargeable battery banks in an electrical load center. The battery bank is a collection of one or more individual battery modules. Given the surplus or deficit power from the electrical system and the state of charge from the previous time step, this object can model the voltage, current, and energy losses with charging and discharging during each time step. The cumulative battery damage can be also modeled and reported at the end of each simulation run.

This object allows the simulation of both lead-acid and Nickel Cadmium batteries. With input parameters derived from specific battery tests, the object is expected to support other battery types, such as Lithium-ion batteries.

The kinetic battery model assumes that part of the battery's energy storage capacity is immediately available in discharging or charging while the rest is chemically bound. As a function of constant current, the battery capacity is related to three parameters: the maximum capacity at infinitesimal current, the capacity ratio of available charges, and the conversion ratio between available charges and bound charges. These parameters are usually obtained via curve fitting based on battery data sheets or test data.

Each individual battery module is modeled as a voltage source in series with an electrical resistance. $\mathrm{KiBaM}$ assumes that the internal resistance is constant and the open circuit voltage varies with the electric current, the state of charge and the operation mode (charging or discharging). For an individual battery module, the open circuit voltage at any time is correlated to the voltage at fully charged/discharged state and three other regression coefficients. These regression coefficients are usually obtained via curve fitting based on battery test data.

The object offers users the option to perform battery life calculation. If battery life is modeled, the user needs to provide a group of coefficients for the correlation between the number of cycles for battery failure and the corresponding cycle range. More detailed information can be found from the Engineering Reference. 
Some representative inputs for this object are provided in the EnergyPlus Reference DataSets (Battery.idf). The model parameters are from the battery library files in Hybrid2 (Manwell et al. 2006). The inputs are described below:

\section{Field: Name}

This alpha field contains the identifying name for the battery bank.

Field: Availability Schedule Name

This alpha field contains the schedule name (ref. Schedule) that describes when the battery is available. A schedule value greater than 0 (usually 1 is used) indicates that electrical energy can be stored or drawn from the battery. A value less than or equal to 0 (usually 0 is used) denotes that the battery is not available.

\section{Field: Zone Name}

This field contains the name of the thermal zone where the battery is located. Entering a valid name of zone here will direct EnergyPlus to include the energy storage losses as heat gains to the named thermal zone. If the battery is not within a thermal zone, this field can be left blank and the thermal energy associated with storage losses is removed from the building model.

\section{Field: Radiative Fraction}

This field contains the fraction of storage losses that enter the zone as long-wave thermal radiation. This numeric filed should have a value between 0.0 and 1.0. The balance of the losses is convective. This field is not used if the previous field for zone name is left blank.

\section{Field: Number of Battery Modules in Parallel}

This field defines the number of modules connected in parallel in the battery bank.

\section{Field: Number of Battery Modules in Series}

This field defines the number of modules connected in series in the battery bank. The total number of modules in a battery bank is equal to the number of modules in parallel times the number of modules in series.

\section{Field: Maximum Module Capacity}

This field indicates the maximum capacity of one battery module. It is evaluated as the total Amp-hours available when a full battery is discharged at infinitesimal current. This capacity is for an individual 
battery module, not for the whole battery bank. The maximum capacity can be found from manufacturer's data or derived from test data by curve fitting.

\section{Field: Initial Fractional State of Charge}

This field describes the initial state of charge in terms of the fraction of maximum capacity as defined in the next field.

\section{Field: Fraction of Available Charge Capacity}

The kinetic battery model assumes that battery is a two-tank electrical energy storage device: an available tank and a bound tank. The available tank can be immediately charged or discharged, while the bound tank can only be charged or discharged via the available tank. This field specifies the fraction of total charge in the battery that is part of the available tank. The ratio of available charge capacity to total capacity is a parameter usually derived from test data by curve fitting.

\section{Field: Change Rate from Bound Charge to Available Charge}

This field specifies the rate at which the charge flows between the available tank and the bound tank. It is a parameter used to calculate the conversion between available charge and chemically bound charge when charging and discharging the battery. This parameter is usually derived from test data by curve fitting.

\section{Field: Fully Charged Battery Open Circuit Voltage}

This field indicates the open circuit voltage for a fully charged battery module. It can be found from manufacturer's data or battery tests.

\section{Field: Fully Discharged Battery Open Circuit Voltage}

This field indicates the open circuit voltage for a fully discharged battery module. It can be found from manufacturer's data or battery tests.

\section{Field: Voltage Change Curve Name for Charging}

This field specifies the name of a rectangular hyperbola type 2 performance curve (ref:

Curve:RectangularHyperbola2 in Performance Curves) that determines the change of open circuit voltage ( $\Delta E$ ) as a function of the battery state of charge in charging. The change of open circuit voltage is relative to a fully discharged battery. The curve has the following form:

$$
\Delta E=\left(C_{1} * X\right) /\left(C_{2}+X\right)+C_{3} * X
$$

where $\mathrm{X}$ is the battery charge divided by the maximum capacity at a given current. More details can be found from the Engineering Reference. 
Field: Voltage Change Curve Name for Discharging

This field specifies the name of a rectangular hyperbola type 2 performance curve (ref:

Curve:RectangularHyperbola2 in Performance Curves) that determines the change of open circuit voltage ( $\Delta E$ ) as a function of the battery state of charge in discharging. The change of open circuit voltage is relative to a fully charged battery. The curve has the following form:

$$
\Delta E=\left(C_{1} * X\right) /\left(C_{2}+X\right)+C_{3} * X
$$

where $\mathrm{X}$ is the removed charge divided by the maximum capacity at a given current. More details can be found from the Engineering Reference.

\section{Field: Internal Electrical Resistance}

This field specifies the battery internal resistance in ohms. In theory, the electrical resistance within the battery varies with the state of charge and depends on whether it is in charging or discharging. In the kinetic battery model, the internal resistance is assumed as constant and the terminal voltage varies with current and state of charge. The internal resistance may be obtained from the battery manufacturer or battery test data. Note that the field is for an individual module, not for the whole battery bank.

\section{Field: Maximum Discharging Current}

This field indicates the maximum current at which the battery can be discharged continuously. The limit on discharge current is usually defined by the battery manufacturer to avoid battery damage. The limit is for an individual battery module.

\section{Field: Cut-off Voltage}

This field specifies the minimum allowable voltage, below which the battery is generally regarded as empty. The cut-off voltage is usually defined by the battery manufacturer and it is for an individual battery module.

\section{Field: Charge Rate Limit}

This field specifies the limit on charging current relative to the remaining charge until the battery is full. This limit reflects the common practice that the charge rate is reduced as the battery gets more charged.

\section{Field: Battery Life Calculation}

This field indicates whether the battery life model is activated in the simulation. If the battery life model is activated, the following five inputs on curve coefficients are required; otherwise, they are not used.

\section{Field: Number of Cycle Bins}


This field specifies the number of equally ranged cycle bins in battery life simulation. If 10 bins are used, the cycle ranges will include $10 \%, 20 \%, \ldots, 100 \%$.

\section{Field: Battery Cycle Life Curve Name}

This field specifies the name of a double exponential decay curve (ref: Curve:DoubleExponentialDecay in Performance Curves) that correlates the cycles of battery failure (CF) and fractional depth of discharge (R). The curve is:

$$
C_{F}=C_{1}+C_{2} e^{C_{3} R}+C_{4} e^{C_{5} R}
$$

\subsubsection{Output Variables for ElectricLoadCenter:Storage:Battery}

Each electrical storage device based on the Kinetic Battery Model (KiBaM) can report the following output variables:

\section{Electrical Storage Mode of Operation[]}

This output reports the battery mode of operation: 0 for idle; 1 for discharging; 2 for charging. It is expected that more operation modes would be added when a smart and active power dispatch controller is used in future.

\section{Electrical Storage State of Charge[Ah]}

The state of charge is expressed as the amount of charge stored in the battery at a point of time. It has the same unit as the maximum capacity. This value is given for an individual battery module.

\section{Electrical Storage Fractional State of Charge[]}

This output is the ratio between the electrical storage state of charge and the maximum capacity.

\section{Electrical Storage Power Into Storage[W] and Electrical Storage Energy Into Storage[J]}

These outputs are total electricity power or energy fed into the battery. This is the rate of charging.

\section{Electrical Storage Energy Into Storage Decrement from Production[J]}

This output is the total electricity energy decremented from electricity production because it has fed into the battery. This output has the opposite sign of "Electrical Storage Energy Into Storage” but is otherwise similar. This decrement output variable is also a meter associated with the resource type "ElectricityProduced" that reduces the metered electricity production to account for power that went into storage after production. 


\section{Electrical Storage Power From Storage[W] and Electrical Storage Energy From Storage[J]}

These outputs are total electricity power or energy drawn from the battery. This is the rate or amount of discharging. The energy from storage output variable is also a meter associated with the resource type "ElectricityProduced" that increases the metered electricity production to account for power that has come back out of storage.

\section{Electrical Storage Total Current[A]}

This output is the current to or from the battery bank depending on whether the battery is in the state of charging or discharging. The value is positive for discharging and negative for charging.

\section{Electrical Storage Total Voltage[V]}

This output is the total terminal voltage of the battery bank.

\section{Electrical Storage Thermal Loss Rate[W] and Electrical Storage Thermal Loss Energy[J]}

These outputs are the thermal power or energy losses from both charging and drawing electrical power in or out of the storage device. These losses are due to the battery internal resistance in charging and discharging.

\section{Electrical Storage Fractional Damage[]}

This output reports the fractional battery life used up at a point of time. For example, a value of 0.4 at the end of one year simulation means that the $40 \%$ of the battery life is used up, so the battery needs to be replaced every two and a half years.

\subsection{Testing and Verification}

The algorithms for the electric battery model were also implemented in MathCAD, which is engineering calculation software, to confirm that the model was correctly implemented. The results from the MathCAD model were identical to the results from the EnergyPlus implementation.

\section{$5.4 \quad$ References}

Bindner, H, T Cronin , P Lundsager, JF Manwell, U Abdulwahid, and I Baring-Gould. 2005. Lifetime Modeling of Lead Acid Batteries. Riso National Laboratory, Roskilde, Denmark.

Downing SD and DF Socie. 1982. Simple rainflow counting algorithms, International Journal of Fatigue, 1982. 
Manwell JF and JG McGowan. 1993. A lead acid battery storage model for hybrid energy systems, Solar Energy 50(5): 399- 405.

Manwell JF, A Rogers, G Hayman, CT Avelar, JG McGowan, U Abdulwahid, and K Wu. 2006. Hybrid2A Hybrid System Simulation Model (Theory Manual), University of Massachusetts. 


\section{Development of a Chiller-Tower Optimization Model}

Cooling tower models are normally used as components assigned to condenser loops to maintain the temperature of the water exiting the cooling tower at (or below) a setpoint. In EnergyPlus, the minimum condenser water temperature currently defines this setpoint. To fully optimize a cooling plant, it is important to optimize cooling tower controls.

As part of an overall chiller plant optimization, the condenser water setpoint can be varied to maximize overall cooling plant efficiency. The optimum tower water temperature is not necessarily the minimum temperature that the towers are capable of providing, but rather the temperature that can meet the particular load at the minimum total energy consumption of operation of all equipment (i.e., tower fans, pumps and compressor). The goal of cooling tower optimization is to maximize the amount of heat discharged into the atmosphere per unit of operating cost invested.

The objective of chiller tower optimization is to set the tower water temperature higher than the more typical tower operation, which uses the minimum condenser water temperature as the control setpoint. This causes the cooling tower fan energy consumption to go down and the compressor energy consumption to go up; but the overall net chiller+tower energy consumption would be less, as illustrated in Figure 6-1. The cooling tower optimization is a function of the load and the weather.

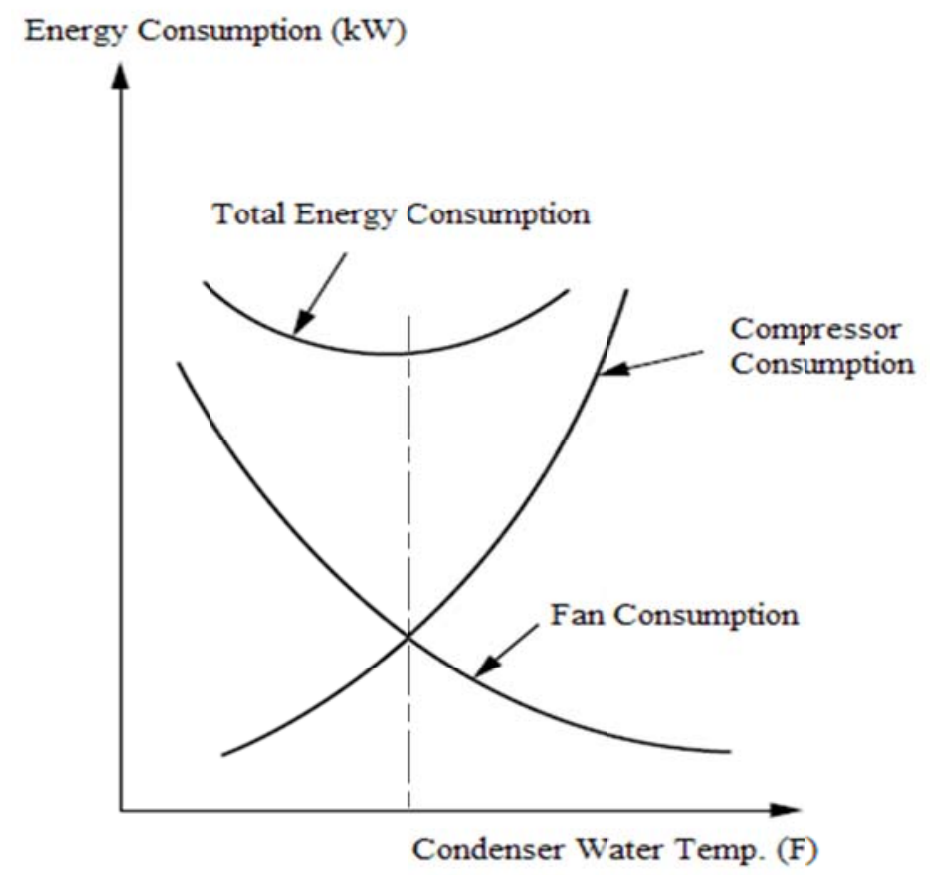

Figure 6-1: Total energy consumption vs. condenser water temperature 


\subsection{Approach}

Cooling towers are water-to-air heat exchangers used to discharge heat into the atmosphere. They cool water by a combination of heat and mass transfer. Cooling towers are capable of cooling water to within $4-5^{\circ} \mathrm{F}$ of the ambient wet-bulb temperature. Water to be cooled is distributed in the tower and a portion of it absorbs heat to change from a liquid to a vapor at constant pressure. This heat of vaporization at atmospheric pressure is transferred from the water remaining in the liquid state into the air stream.

The cooling tower is modeled in EnergyPlus as a counter flow heat exchanger with a single speed, two-speed or variable-speed fan. In Version 6.0 of EnergyPlus, the user must define tower performance using either product of heat transfer coefficient and area (UA) or nominal tower capacity at a specific rating point. Regardless of the method selected, the design airflow rate and corresponding fan power must be specified or auto sized. The cooling tower will attempt to maintain the temperature of the water exiting the cooling tower at a setpoint that is the minimum condenser water temperature. This does not necessarily result in minimum net energy consumption of chiller and cooling tower. Cooling tower optimization can be used to minimize net energy consumption, but this is not currently modeled.

In cooling tower optimization, the setpoint temperature of water leaving the cooling tower is set higher than the (usually constant) condenser entering setpoint. When this setpoint is increased, the energy consumption of cooling tower fan drops, while the energy consumption of chiller compressor increases. Although chiller compressors can typically be responsible for $60 \%$ of total energy consumption of cooling systems annually, the cooling tower optimization would result in a net reduction of compressor and tower fan energy consumption.

The optimized condenser entering temperature is a direct function of the outside air wet-bulb and part load ratio. For example, if chiller load is at $60 \%$, ambient wet-bulb is $65^{\circ} \mathrm{F}$, and minimum condenser water temperature is $60^{\circ} \mathrm{F}$, during "normal" operation the tower tries to drive water temperature to $60^{\circ} \mathrm{F}$, but it can only reach $73^{\circ} \mathrm{F}$ at these conditions. To get to $73^{\circ} \mathrm{F}$, tower fans are at full speed. However, the chiller-tower optimization algorithm calculates that $79^{\circ} \mathrm{F}$ is optimal for the system. This means that the tower energy goes down, chiller energy goes up, but the total energy is lower than "normal".

The chiller-tower optimization scheme uses one curve to determine the optimum condenser entering water temperature for a given timestep and two other curves to place boundary conditions on the “optimized” setpoint value. The optimized condenser entering water temperature is not going to be valid every timestep and will be limited algorithmically by two boundary curves. The first of these boundary curves (i.e., minimum tower design wet-bulb temperature condition) is given by: 
$\operatorname{MinDsnWB}=\mathrm{A}_{1}+\mathrm{A}_{2} * \mathrm{OaWb}+\mathrm{A}_{3} * \mathrm{WPLR}+\mathrm{A}_{4} * \mathrm{TwrDsnWB}+\mathrm{A}_{5} * \mathrm{NF}$

Where,
$\mathrm{A}_{1}-\mathrm{A}_{5}$
$=$ Curve coefficients
$\mathrm{OaWb}$
$=$ Outside air wet-bulb for current timestep, ${ }^{\circ} \mathrm{C}$
TwrDsnWB
$=$ Tower design inlet air wet-bulb temperature, ${ }^{\circ} \mathrm{C}$
WPLR
$=$ Weighted part load ratio (WPLR)
= ChillerCoolingLoadThisTimestep / NominalChillerCapacity
NF
$=$ Normalized condenser water flow per unit of tower capacity, $\mathrm{m}^{3} / \mathrm{W}$
= Design Tower Flow Rate $/$ Design Tower Capacity
(typically $5.382 \mathrm{E}-8 \mathrm{~m}^{3} / \mathrm{s}$, i.e., $3 \mathrm{gpm} / \mathrm{ton}$ )

MinDsnWB is compared against the design tower wet-bulb temperate. This curve is usually a function of WPLR and NF if NF is constant at 5.382E-8 $\mathrm{m}^{3} / \mathrm{s}$ (3 gpm/ton) as shown in Figure 6-2.

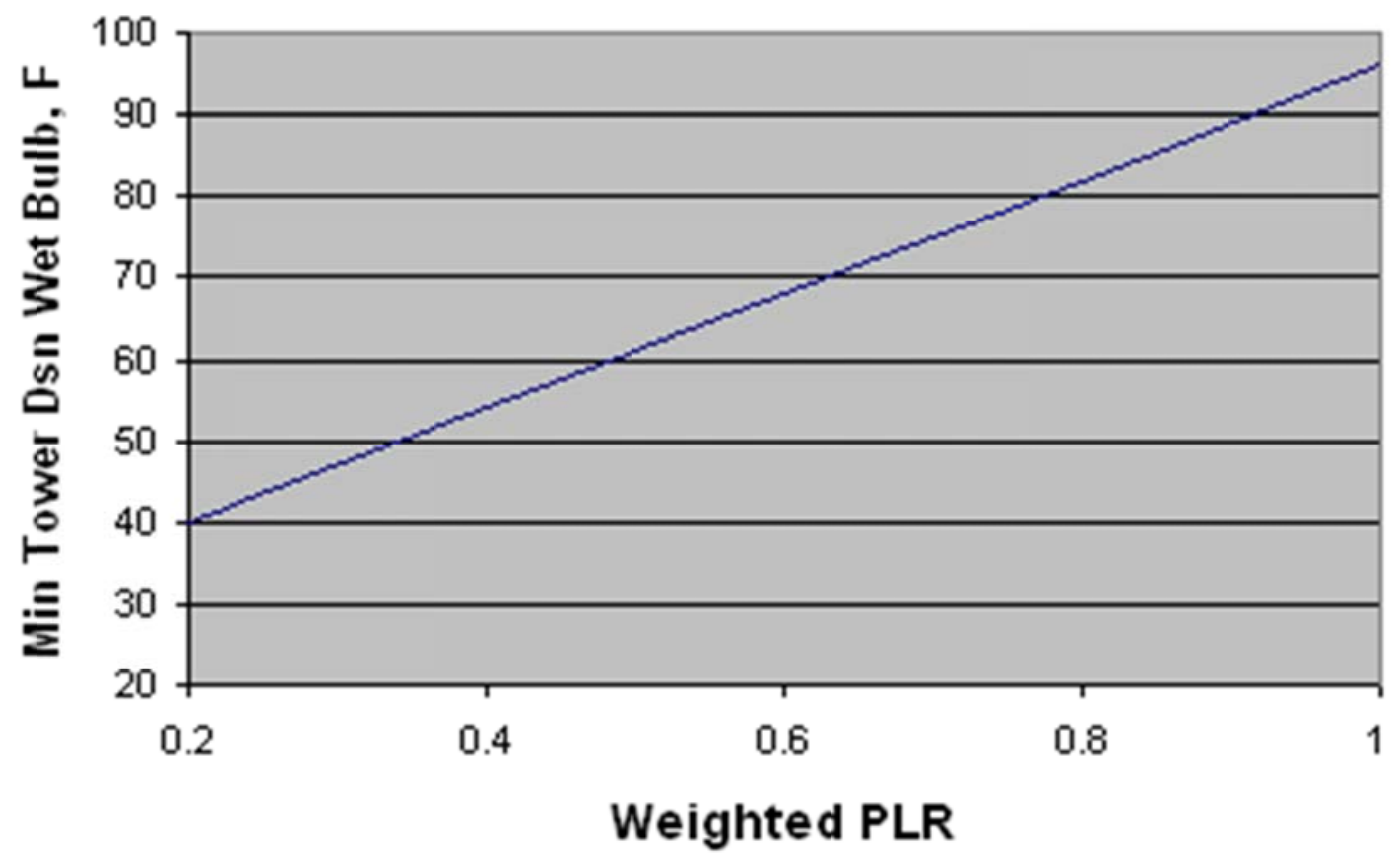

Figure 6-2: Minimum tower design wet-bulb temperature boundary condition 
The second boundary curve (i.e., minimum outdoor air wet-bulb temperature condition) is given by:

$$
\text { MinActualWb }=\mathrm{B}_{1}+\mathrm{B}_{2} * \operatorname{MinDsnWB}+\mathrm{B}_{3} * \mathrm{WPLR}+\mathrm{B}_{4} * \text { TwrDsnWB }+\mathrm{B}_{5} * \mathrm{NF}
$$

Where,

$$
\begin{array}{ll}
\mathrm{B}_{1}-\mathrm{B}_{5} & =\text { Curve coefficients } \\
\text { MinDsnWB } & =\text { From first boundary equation, }{ }^{\circ} \mathrm{C} \\
\text { TwrDsnWB } & =\text { Tower design inlet air wet-bulb temperature, }{ }^{\circ} \mathrm{C} \\
\text { WPLR } & =\text { ChillerCoolingLoadThisTimestep } / \text { NominalChillerCapacity } \\
\text { NF } & =\text { Normalized condenser water flow per unit of tower capacity, } \mathrm{m}^{3} / \mathrm{W} \\
& =\text { Design Tower Flow Rate } / \text { Design Tower Capacity } \\
& \text { (typically } 5.382 \mathrm{E}-8 \mathrm{~m}^{3} / \mathrm{s}, \text { i.e., } 3 \text { gpm/ton) }
\end{array}
$$

MinActualWb is compared against this timestep's outside air wet-bulb temperature. This curve is usually a function of MinDesignWB, WPLR and TwrDesignWB. If TwrDesignWB is constant at $25.6^{\circ} \mathrm{C}$ $\left(78^{\circ} \mathrm{F}\right.$ ), and NF is equal to $5.382 \mathrm{E}-8 \mathrm{~m}^{3} / \mathrm{s}$ ( $3 \mathrm{gpm} / \mathrm{ton}$ ), the curve can be depicted as shown in Figure 6-3.

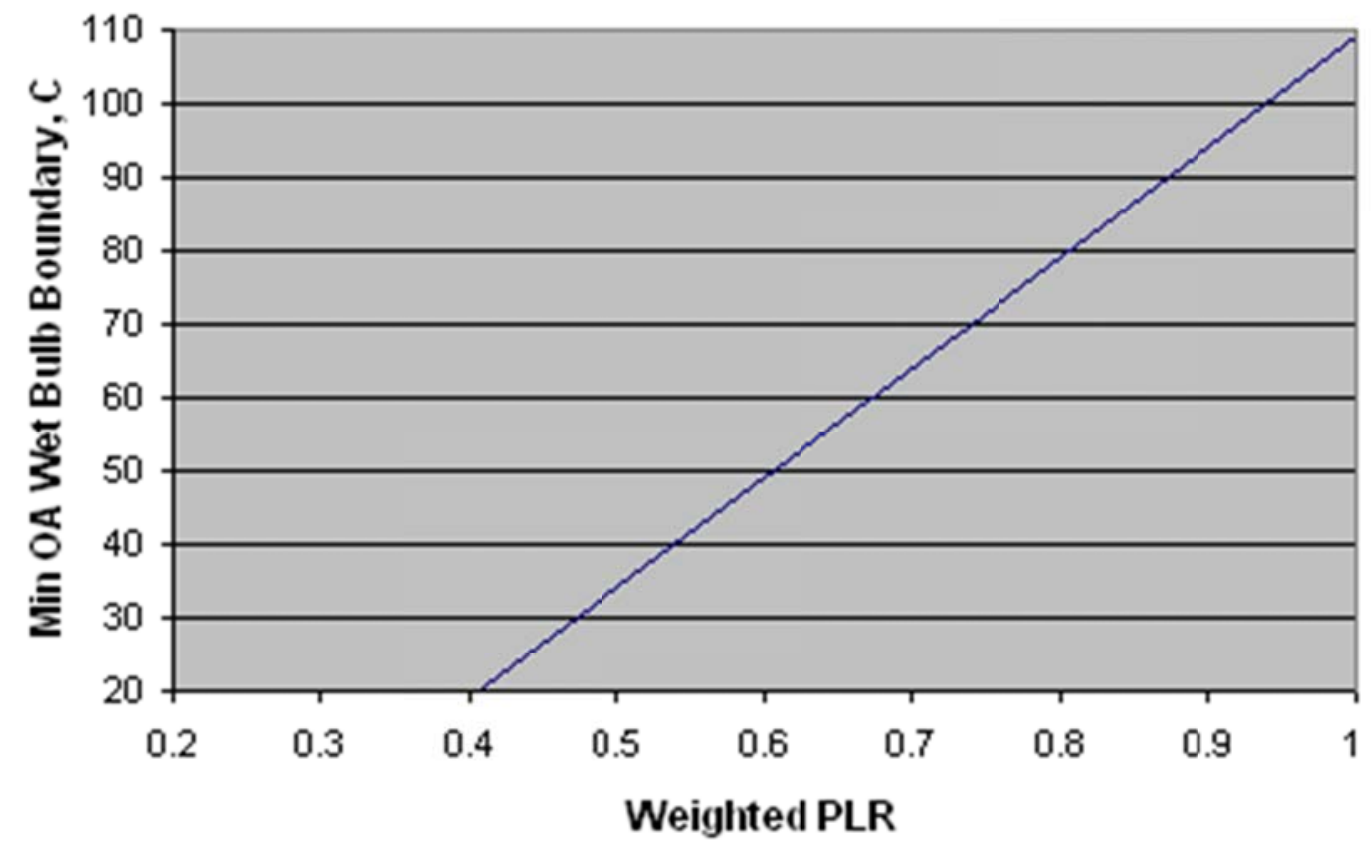

Figure 6-3: Minimum outdoor air wet-bulb temperature boundary condition 
The optimized condenser entering water temperature is calculated with this equation:

$$
\text { OptCondEntTemp }=\mathrm{C}_{1}+\mathrm{C}_{2} * \mathrm{OaWb}+\mathrm{C}_{3} * \mathrm{WPLR}+\mathrm{C}_{4} * \mathrm{TwrDsnWB}+\mathrm{C}_{5} * \mathrm{NF}
$$

where,

$$
\begin{array}{ll}
\mathrm{C}_{1}-\mathrm{C}_{5} & =\text { Curve coefficients } \\
\text { OaWB } & =\text { Outdoor air wet-bulb temerature, }{ }^{\circ} \mathrm{C} \\
\text { TwrDsnWB } & =\text { Tower design inlet air wet-bulb temperature, }{ }^{\circ} \mathrm{C} \\
\text { WPLR } & =\text { ChillerCoolingLoadThisTimestep } / \text { NominalChillerCapacity } \\
\mathrm{NF} & =\text { Normalized condenser water flow per unit of tower capacity, } \mathrm{m}^{3} / \mathrm{W} \\
& =\text { Design Tower Flow Rate } / \text { Design Tower Capacity } \\
& \text { (typically } 5.382 \mathrm{E}-8 \mathrm{~m}^{3} / \mathrm{s}, \text { i.e., } 3 \text { gpm/ton) }
\end{array}
$$

The optimized condenser entering water temperature as a function of weighted part load ratio at various outdoor air wet-bulb temperatures can be depicted as shown in Figure 6-4.

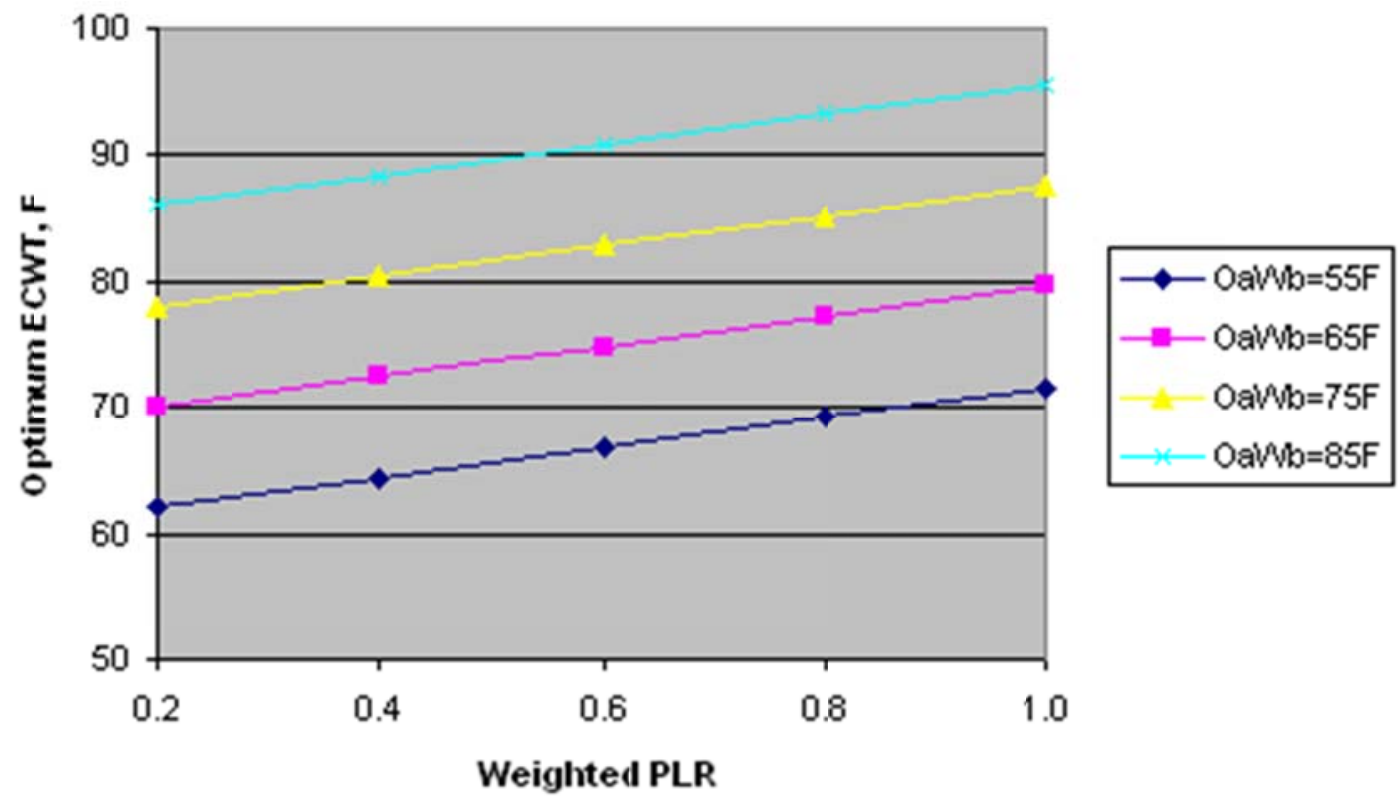

Figure 6-4: Optimized condenser entering water temperature as a function of weighted part load ratio at various outdoor air wet-bulb temperatures 
The optimized condenser entering water temperature is calculated but is not necessarily used each timestep. If OptCondEntTemp does not fall within the bounds established by MinDsnWB and MinActualWb, then the value from the Default Condenser Entering Water Temperature Schedule is used for the Condenser Entering Water Setpoint instead.

\subsection{Descriptions of Input Fields}

The chiller-tower optimization scheme uses one curve to determine the optimum condenser entering water temperature for a given timestep and two other curves to place boundary conditions on the “optimized” setpoint value. It is proposed to implement this feature by the addition of a new Setpoint Manager object attached to the condenser loop.

\section{Field: Name}

A unique, user-assigned name for an instance of the optimized condenser entering water setpoint manager.

\section{Field: Control Variable}

The type of variable that will be controlled. There is only one choice for this type of setpoint manager: Temperature.

\section{Field: Default Condenser Entering Water Temperature Schedule Name}

This schedule should define the default condenser entering water temperature setpoint. This scheduled setpoint value is only used in a given timestep if the "optimized" setpoint value (see the Optimized Condenser Entering Water Temperature Curve Name field) does not fall within its prescribed boundary conditions.

\section{Field: Minimum Design Wet-bulb Temperature Curve Name}

The curve name associated with the coefficients in the equation used to determine the minimum design tower wet-bulb referenced by the minimum outside air wet-bulb temperature curve below. The value from this curve is compared to the tower design wet-bulb each timestep to establish one of the governing boundaries over the optimized condenser entering water temperature setpoint calculation. This curve must be quad-linear (Curve:QuadLinear) and is defined as: 


$$
\mathrm{T}=\mathrm{C} 1+\mathrm{C} 2 * \mathrm{OaWb}+\mathrm{C} 3 * \mathrm{WPLR}+\mathrm{C} 4 * \mathrm{TwrWb}+\mathrm{C} 5 * \mathrm{NF}
$$

where,

$$
\begin{array}{ll}
\mathrm{OaWb} & =\text { Outside air wet-bulb for current timestep, }{ }^{\circ} \mathrm{C} \\
\mathrm{WPLR} & =\text { Weighted part load ratio, dimensionless } \\
\mathrm{TwrWb} & =\text { Design tower wet-bulb boundary condition, }{ }^{\circ} \mathrm{C} \\
\mathrm{NF} & =\text { Normalized condenser water flow per unit of tower capacity, } \mathrm{m}^{3} / \mathrm{W}
\end{array}
$$

\section{Field: Minimum Outside Air Wetbulb Temperature Curve Name}

The curve name associated with the coefficients in the equation used to determine the minimum actual wetbulb referenced by the optimized condenser entering water temperature curve. The value from this curve is compared the actual outside wet-bulb each timestep to establish one of the governing boundaries over the optimized condenser entering water temperature setpoint calculation. This curve must be quadlinear (Curve:QuadLinear) and is defined as:

$$
\mathrm{T}=\mathrm{C} 1+\mathrm{C} 2 * \mathrm{OaWb}+\mathrm{C} 3 * \mathrm{WPLR}+\mathrm{C} 4 * \mathrm{TwrWb}+\mathrm{C} 5 * \mathrm{NF}
$$

where,

$$
\begin{array}{ll}
\mathrm{OaWb} & =\text { Outside air wet-bulb for current timestep, }{ }^{\circ} \mathrm{C} \\
\mathrm{WPLR} & =\text { Weighted part load ratio, dimensionless } \\
\mathrm{TwrWb} & =\text { Design tower wet-bulb boundary condition, }{ }^{\circ} \mathrm{C} \\
\mathrm{NF} & =\text { Normalized condenser water flow per unit of tower capacity, } \mathrm{m}^{3} / \mathrm{W}
\end{array}
$$

\section{Field: Optimized Condenser Entering Temperature Curve Name}

The curve name associated with the coefficients in the optimized condenser entering water temperature equation. The value from this curve is used to calculate the optimized condenser entering water temperature for each timestep. If this “optimized” setpoint does not fall within the bounds established by the two boundary conditions, then the value from the Default Condenser Entering Water Temperature Schedule is used for the Condenser Entering Water Setpoint for that timestep. This curve must be quadlinear (Curve:QuadLinear) and is defined as: 


$$
\mathrm{T}=\mathrm{C} 1+\mathrm{C} 2 * \mathrm{OaWb}+\mathrm{C} 3 * \mathrm{WPLR}+\mathrm{C} 4 * \mathrm{TwrWb}+\mathrm{C} 5 * \mathrm{NF}
$$

where,

$$
\begin{array}{ll}
\mathrm{OaWb} & =\text { Outside air wet-bulb for current timestep, }{ }^{\circ} \mathrm{C} \\
\text { WPLR } & =\text { Weighted part load ratio, dimensionless } \\
\text { TwrWb } & =\text { Design tower wet-bulb boundary condition, }{ }^{\circ} \mathrm{C} \\
\mathrm{NF} & =\text { Normalized condenser water flow per unit of tower capacity, } \mathrm{m}^{3} / \mathrm{W}
\end{array}
$$

\section{Field: Minimum Lift}

This field establishes the minimum lift allowed. Lift is generally thought of as the difference between condenser refrigerant pressure and the evaporator refrigerant pressure. Using defined pressure and temperature relationships, lift also can be related to the difference between the leaving chilled water and the leaving condenser water temperature. Further, when the leaving condenser water temperature and condenser water flow are constant, the entering condenser temperature can be used as a proxy for lift. Because most condenser water systems are designed for constant flow, entering condenser temperature is the most common metric for lift. If the calculated Condenser Entering Water Setpoint falls below (TEvapLvgWater + MinimumLift), then the Condenser Entering Water Setpoint is reset to equal TEvapLvgWater + MinimumLift. The units for this field are ${ }^{\circ} \mathrm{C}$ TD. Default is $11.1^{\circ} \mathrm{C}\left(20^{\circ} \mathrm{F}\right)$.

\section{Field: Maximum Condenser Entering Temperature}

This field establishes the maximum condenser entering water setpoint temperature allowed. If the scheduled or calculated setpoint is above TCondEntMax, then TCondEntSetpoint is reset to equal TCondEntMax. The units for this field are ${ }^{\circ} \mathrm{C}$.

\section{Field: Cooling Tower Design Inlet Air Wet-Bulb Temperature}

This field defines the reference wet-bulb temperature used to size the cooling tower. Typically, the design condenser entering water temperature equals TwrRefOaWb + TowerApproachTD. The units for this field are ${ }^{\circ} \mathrm{C}$.

\section{Field: Setpoint Node or NodeList Name}

This field defines the condenser node being controlled. 


\subsection{Testing and Verification}

The new objects were tested using modified EnergyPlus example files for both variable speed and two speed cooling towers. As it was expected, the chiller electric consumption increases while fan electric consumption goes down, and this results in lower net energy consumption. This holds true at lower setpoints (e.g. $18-26^{\circ} \mathrm{C}$ ). 


\section{Summary}

This report summarizes the model enhancement activities for EnergyPlus that PNNL performed in FY10 and FY11. Each task with the corresponding section number is listed below:

- Improve Autosizing of HVAC Components - Section 2

- Life-Cycle Costing to Evaluate Energy Efficiency Upgrades - Section 3

- Develop New Model to Capture Transformer Losses - Section 4

- Enhance the Model for Electric Battery Storage - Section 5

- Develop New Model for Chiller-Tower Optimization - Section 6

The modeling strategy and input/output variable for each task were discussed in detail in each section. Each feature listed above was identified and selected to be further enhanced or developed to help achieve DOE Building Technology Program’s strategic goal. 


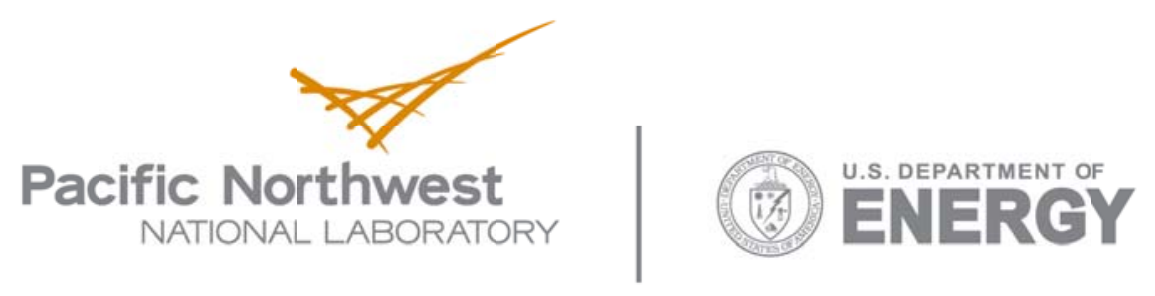

902 Battelle Boulevard

P.O. Box 999

Richland, WA 99352

1-888-375-PNNL (7665)

www.pnl.gov 